\title{
Portable X-Ray, K-Edge Heavy Metal Detector
}

by

V. Fricke

Westinghouse Savannah River Company

Savannah River Site

Alken, South Carolina 29808

J. Lee

T. Jensen

Ames Laboratory
RECEIVEP

NOY 053989

OSTI

DOE Contract No. DE-AC09-96SR18500

This paper was prepared in connection with work done under the above contract number with the U.S. Department of Energy. By acceptance of this paper, the publisher and/or recipient acknowledges the U.S. Government's right to retain a nonexclusive, royalty-free license in and to any copyright covering this paper, along with the right to reproduce and to authorize others to reproduce all or part of the copyrighted paper. 


\section{DISCLAIMER}

This report was prepared as an account of work sponsored by an agency of the United States Government. Neither the United. States Government nor any agency thereof, nor any of their employees, makes any warranty, express or implied, or assumes any legal liability or responsibility for the accuracy, completeness, or usefulness of any information, apparatus, product, or process disclosed, or represents that its use would not infringe privately owned rights. Reference herein to any specific commercial product, process, or service by trade name, trademark, manufacturer, or otherwise does not necessarily constitute or imply its endorsement, recommendation, or favoring by the United States Government or any agency thereof. The views and opinions of authors expressed herein do not necessarily state or reflect those of the United States Government or any agency thereof.

This report has been reproduced directly from the best available copy.

Available to DOE and DOE contractors from the Office of Scientific and Technical Information, P.O. Box 62, Oak Ridge, TN 37831; prices available from (615) 576-8401.

Available to the public from the National Technical Information Service, U.S. Department of Commerce, 5285 Port Royal Road, Springfield, VA 22161. 


\section{DISCLAIMER}

Portions of this document may be illegible in electronic image products. Images are produced from the best available original document. 


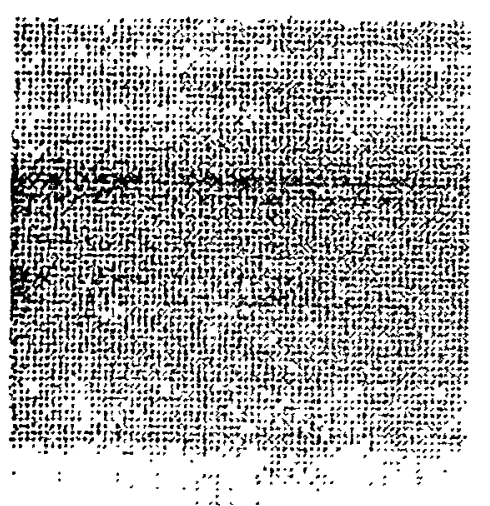

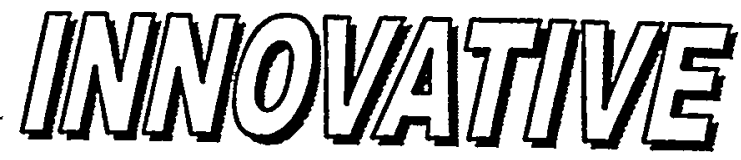

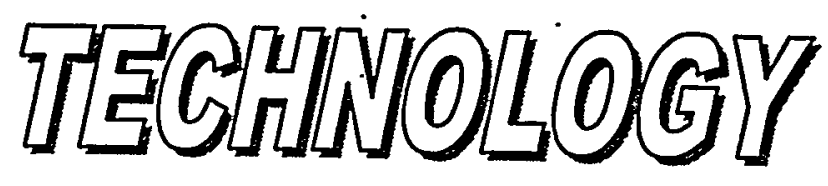

Summary Report.
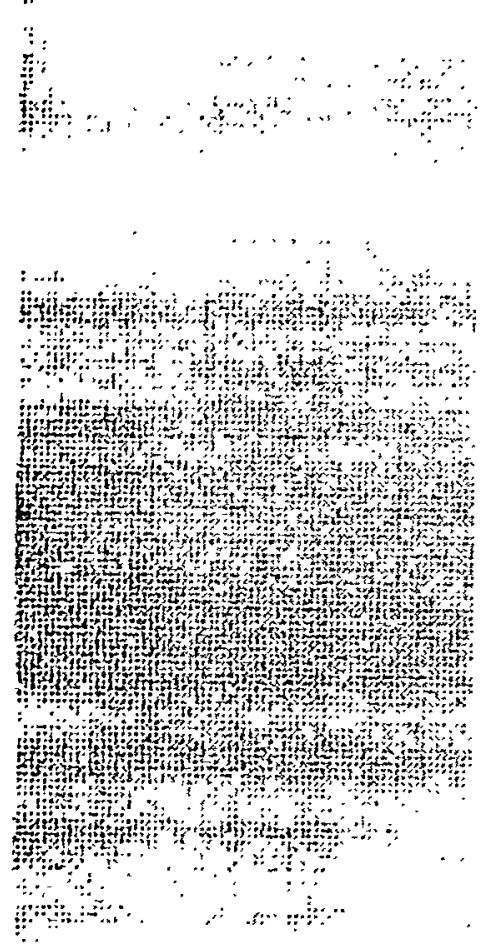

\section{Portable X-Ray, K-Edge Heavy Metal Detector}

OST Reference \# 134

Deactivation and Decommissioning Focus Area \& Characterization, Monitoring, and Sensor Technology Program
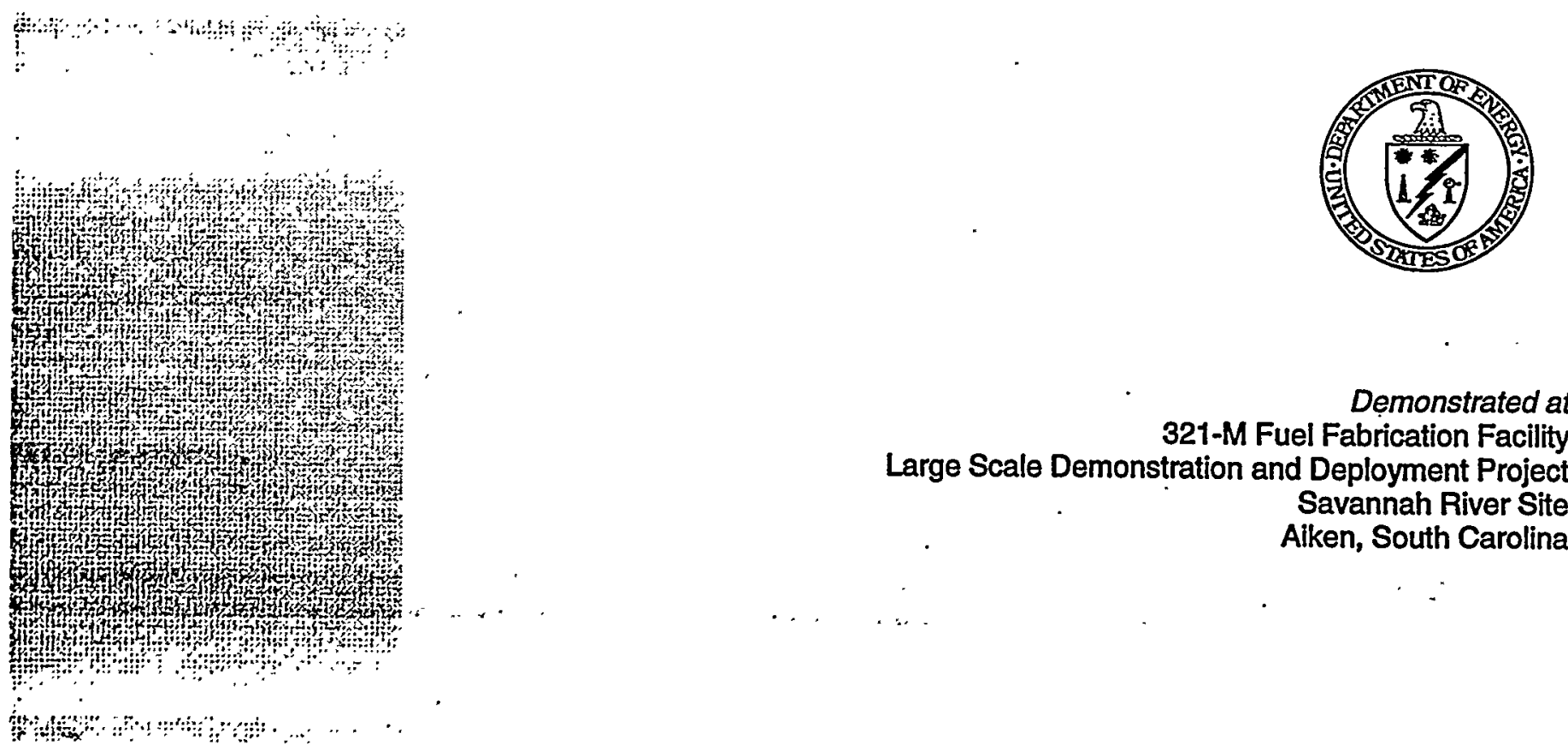


\section{INNDOVIIIIME}

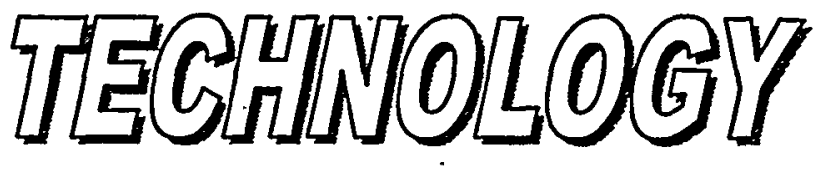

Summary Report

\section{Purpose of this document}

Innovative Technology Summary Reports are designed to provide potential users with the information they need to quickly determine if a technology would apply to a particular environmental management problem. They are also designed for readers who may recommend that a technology be considered by prospective users.

Each report describes a technology, system, or process that has been developed and tested with funding from DOE's Office of Science and Technology (OST). A report presents the full range of problems that a technology, system, or process will address and its advantages to the DOE cleanup in terms of system performance, cost, and cleanup effectiveness. Most reports include comparisons to baseline technologies as well as other competing technologies. Information about commercial availability and technology readiness for implementation is also included. Innovative Technology Summary Reports are intended to provide summary information. References for more detailed information are provided in an appendix.

Efforts have been made to provide key data describing the performance, cost, and regulatory acceptance of the technology. If thị information was not available at the time of publication, the omission is noted.

All published Innovative Technology Summary Reports are available on the OST web site at http://OST.em.doe.gov under "Publications." 


\section{TABLE OF CONTENTS}

1 SUMMARY

2 TECHNOLOGY DESCRIPTION

3 PERFORMANCE

4 TECHNOLLOGY APPLICABILITY AND ALTERNATIVES

5 cost

22

6 REGULATORY AND POLICY ISSUES

7 LESSONS LEARNED

APPENDICES

A References

B Technology Cost Comparison 


\section{SECTION 1}

\section{SUMMARY}

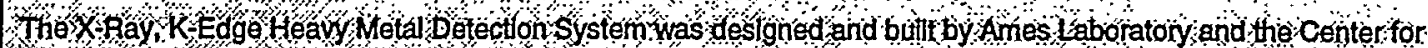
Nondestructive Evaluationat owa state university the sy stemuses a o frame Inspection thead with an X ray tube: moúrited on one side ô the frame and an Inaging unit and a high purity gemanium detector on the other side. The Inspection head is portable and can be easily positioned around ventilation ducts and pipes up to 36 inches in diameter. Wide angle and narow beam $X$-ray shots are used to identify the type of holdup materat and the amount of the

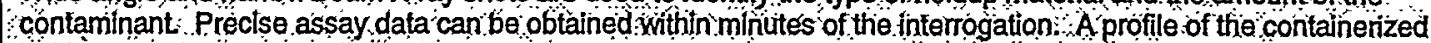
holdup material and aspermanent tecord of the measurementráre immediately available:

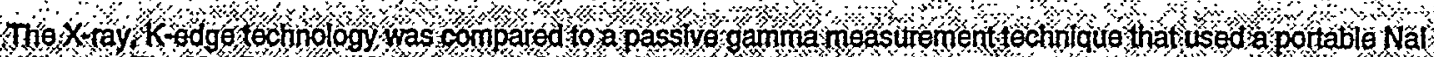

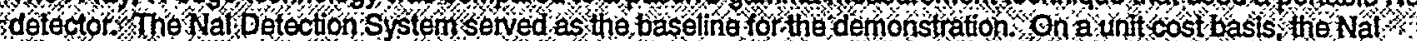

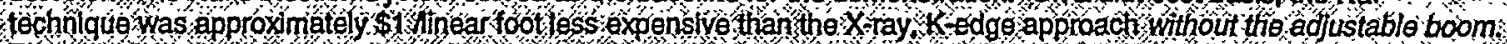

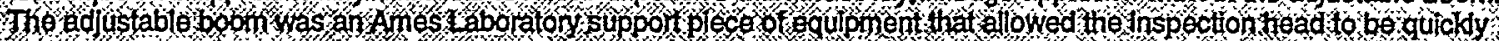

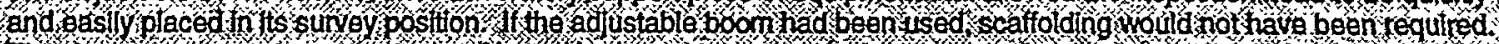

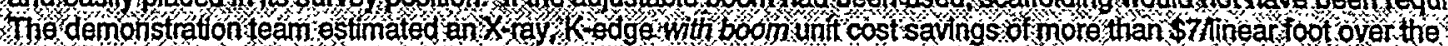

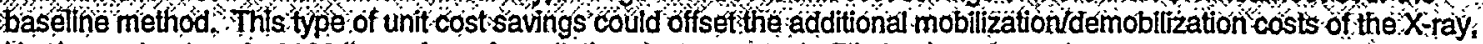
Kedge technology in 6000 linear feet of ventilation duct surveyed. Elimination of onestime costs associated with the first deptoyment of the fechnology, and warmer weather and efficiency enhancing improvements could have lowered the break-even point even more. Although the Nal detection method was less expensive than the X-ray Kedge withoutt boom technology; it was not as precise offered no spatial resolition end did not provide a pennanent charactenzation

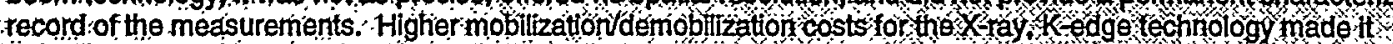

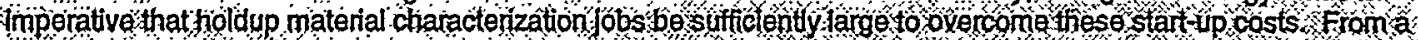

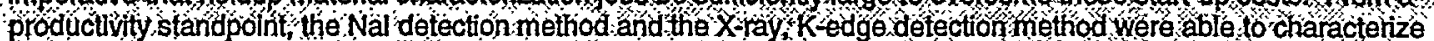

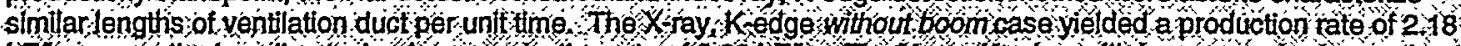

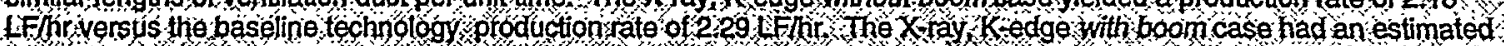

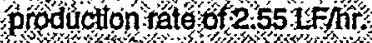

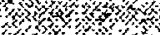

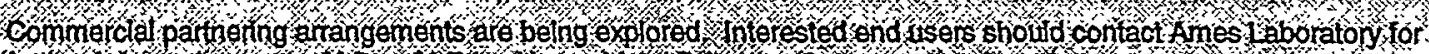

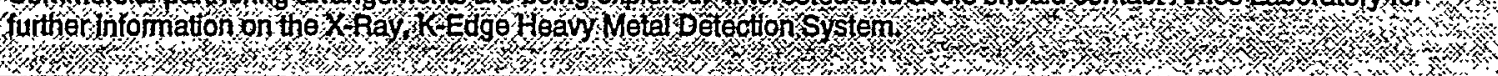

\section{Technology Summary}

The X-Ray, K-Edge Heavy Metal Detection System uses a C-frame inspection head with an X-ray tube mounted on one side of the frame and an imaging unit and high purity germanium detector on the other side (Fig. 1). A broad spectrum of $X$-rays is directed from the $X$-ray tube, through containerized holdup material, to the imaging unit's phosphor screen. If an imaging unit snapshot shows a holdup material profile that merits investigation, a thorough narrow beam analysis of that area will be initiated.

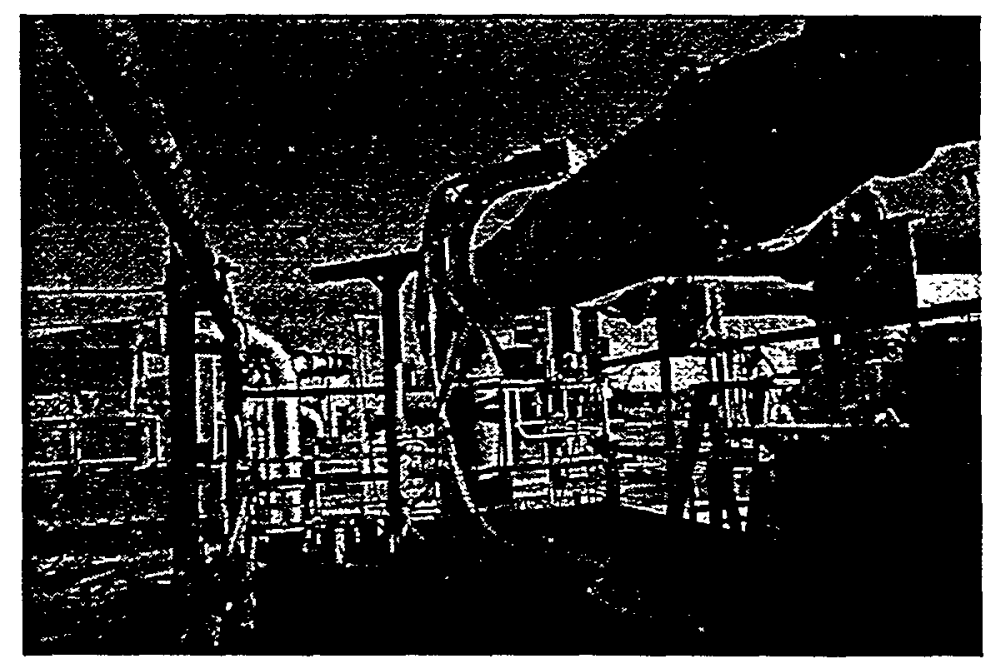

Figure 1. Inspection Head on 20-Inch Diameter Ventilation Duct

Wide angle snapshots, narrow beam interrogation, and mathematical interpolation between the measured data points will allow system operators to calculate the total amount of contaminants in each section of a container. At the 321-M Facility, the X-ray, K-edge technology has been used 
to determine the type and amount of heavy metal contaminants in facility ventilation ducts and. pipes.

\section{Problem}

Ventilation ducts, piping, and process equipment in DOE Complex facilities contain an assortment of heavy metal contaminants. Uranium and plutonium are two of the more prevalent heavy metal contaminants. The presence of these heavy metals is hard to detect because alpha particles emitted from these contaminants are easily stopped by container walls. With the use of conventional survey instruments, low energy gammas emitted from these radioactive heavy metals can be measured. Although the presence of uranium and plutonium can be detected by passive gamma measurements, it is difficult to accurately quantify the amount of these contaminants using the passive gamma method. Different container geometries and varying wall thicknesses complicate, and ultimately degrade, the passive gamma measurements. The X-Ray, K-Edge Heavy. Metal Detection System does not rely on gamma ray emissions from the holdup material and is capable of providing a quantifiable, non-destructive evaluation of containers with different geometries and wall thicknesses.

For thirty-five years, the 321-M Facility fabricated fuel assemblies for the SRS production reactors. The manufacturing process, combined with high ventilation flow rates, left dust, cuttings, and other forms of highly enriched uranium (HEU) in the building ventilation ducts and process equipment enclosures. The conventional method for holdup material measurement was . a Nal hand-held detector with a resolution of $+100 \%,-50 \%{ }^{1}$ A more precise characterization method was sought. The X-Ray, K-Edge Heavy Metal Detection System satisfies this need and is an attractive alternative to the traditional technologies.

\section{How It Works}

K-edge densitometry is the non-destructive inspection technique used by this technology. This method is based on the characteristic absorption of $X$-rays in heavy metals. If an $X$-ray has just enough energy to liberate one of the K-shell electrons, there will be a sharp increase in the rate of $X$-ray absorption in the sample material and an attendant intensity drop at the $X$-ray detector. This 'decrease in intensity is called the K-edge drop and is depicted in Figure 2. The energy at which the
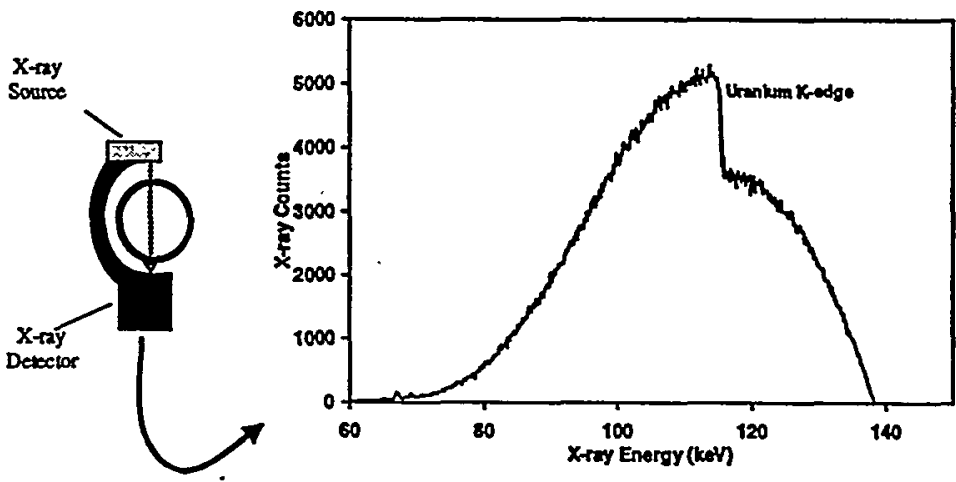

Figure 2. K-Edge Drop for Actual X-Ray Shot abrupt change in intensity occurs identifies the type of contaminant. The amount of contaminant present can be calculated based on the magnitude of the intensity change.

The X-ray, K-edge measurement system consists of three major subsystems: an $X$-ray generator, a detection system, and a computer-controlled data acquisition system. These subsystems work together to generate an image of an area that may contain holdup material. Examination of the $X$-ray spectrum yields information on the elemental makeup and quantity of the holdup material. 


\section{Potential Markets}

The X-ray, K-edge technology is best suited for environments where container geometry and container wall thickness are not well known and/or where the holdup material has an irregular distribution. The X-Ray, K-Edge Heavy Metal Detection System can be used on all DOE and private sector D\&D projects where a precise, nondestructive evaluation of containerized heavy metal holdup material is required.

\section{Advantages Over the Baseline}

The X-ray, K-edge system has several advantages over the Nal hand-held detector and other competing passive gamma measurement technologies. The Nal detector was the baseline technology for this demonstration. The advantages include:

\begin{tabular}{|l|l|}
\hline \multicolumn{1}{|c|}{ Category } & \multicolumn{1}{|c|}{ Comment } \\
\hline Accuracy & $\begin{array}{l}\text { Precision for small areas is } \pm 10 \%, \text { for large areas precision is } \\
\text { comparable to } \mathrm{Nal}(+100 \%,-50 \%)\end{array}$ \\
\hline Spatial Resolution & $\begin{array}{l}\text { Provides a profile or map of contaminants in the container with } \\
\text { spatial resolution on the order of one millimeter }\end{array}$ \\
\hline Documentation & $\begin{array}{l}\text { Provides a real-time and permanent record of assay } \\
\text { measurement }\end{array}$ \\
\hline Container Configuration & \begin{tabular}{l} 
Insensitive to container geometry and container wall thickness \\
\hline
\end{tabular} \\
\hline
\end{tabular}

Shortfalls or disadvantages for the X-ray, K-edge technology include:

- Unit Cost greater for X-ray, K-edge without adjustable boom than for the Nal portable detector. (Use of an adjustable boom could flip this cost relationship and make X-ray, K-edge the low "unit cost" technology.)

- Maintenance Cost potentially greater for the X-ray, K-edge System than for conventional passive gamma measurement systems.

- Mobilization/Demobilization Cost for an X-ray, K-edge deployment is greater than Mob/Demob cost for the Nal Detection System. (Use of an adjustable boom could significantly reduce the mobilization/demobilization cost.)

- Safety margins are somewhat less for X-ray, K-edge due to the technology's use of X-rays.

- More Training is required to operate the $X$-ray, K-edge System than conventional passive gamma measurement systems.

- Interpretation of Data is potentially more difficult for X-ray, K-edge results than for Nal results.

- Waste Generation (during mobilization/demobilization efforts) are potentially greater for Xray, K-edge than for conventional passive gamma measurement systems if deployed in a contaminated area.

\section{Demonstration Summary}

This report covers the period from February to March, 1999.

The SRS Facilities Decommissioning Division, with the help of the Savannah River Technology Center (SRTC), sponsored the technology demonstration. The Center for Nondestructive Evaluation and Ames Laboratory at lowa State University provided the equipment, operated the hardware, and interpreted the results. 


\section{Demonstration Site Description}

The X-Ray, K-Edge, Heavy Metal Detection System was demonstrated at the Savannah River Site's 321-M Fuel Fabrication Facility. ${ }^{2}$ The demonstration was performed on the roof portion of the Lathe Enclosures Exhaust System. Figure 3 shows the ventilation exhaust system without the scaffolding in place. Figure 4 shows the same job site with scaffolding. The object covered by the tarp in Figure 4 is the inspection head. The inspection head is mounted on a portable vertical stand. The stand and inspection head are shown in Figure 1.

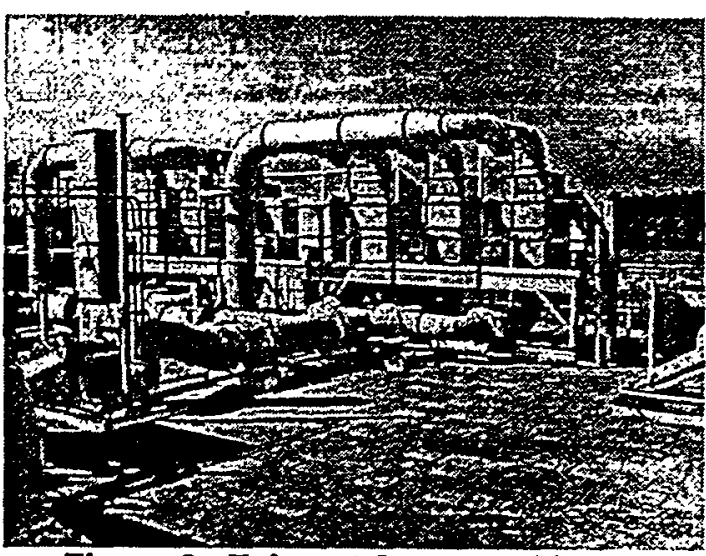

Figure 3. Exhaust System without Scaffolding

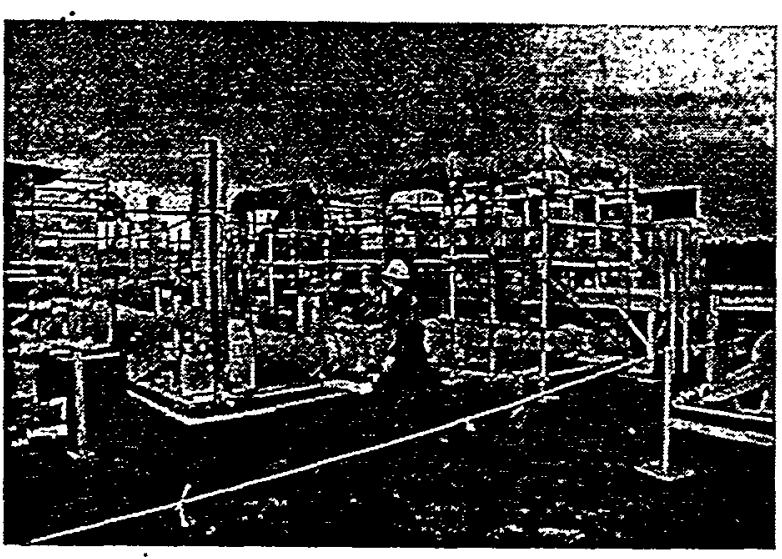

Figure 4. Exhaust System with Scaffolding

The southern exhaust system serves the numerically-controlled lathe and the northern exhaust system serves the Gisholt lathe. Wide angle images and narrow beam spectroscopic measurements were made on the afternoon of February 20, 1999 and on night shift from February 22 to February 25, 1999.

Lathe operations throughout the facility's life generated uranium dust, uranium turnings, and small pieces of scrap uranium. The uranium was highly enriched uranium with an estimated U-235 enrichment fraction of 70 percent: ${ }^{3}$ Some of the uranium made its way past dedicated cyclone separators and was deposited in the lathe system ventilation exhaust ducts. .Early characterization efforts tried to locate and quantify the suspected holdup material in order to address potential criticality concems, safeguards and security issues, material control \& accountability considerations, and to make better informed decisions on future D\&D work.

\section{Key Demonstration Results}

As a result of the demonstration, the $X$-ray, $K$-edge technology team discovered turnings and nuggets of uranium material in the 84 feet of surveyed exhaust duct. X-ray images located the uranium: The HPGe detector and a data acquisition package allowed operators to quantify the deposits. The $\mathrm{X}$-ray, $\mathrm{K}$-edge device proved to be more precise than a Nal detector in quantifying holdup material. Non-destructive measurements with the $X$-ray, K-edge device yielded results with a precision of $\pm 10 \%$ for small areas. The ability to visually interrogate the inside of a duct and provide a real-time documented record of the effort was another advantage over the baseline. The Nal detection method is also susceptible to high background levels. $X$-ray, $K$ edge measurements are much less sensitive to the influence of high backgrounds rates. The $X-$ ray, K-edge detector and the $\mathrm{Nal}$ detector experienced comparable characterization rates (linear feet analyzed per hour). The X-ray, K-edge technology is not adversely affected by the presence of unknown material in the sample (or matrix) material or an unknown material makeup for the container that encloses the sample. Nal measurements may be corrupted by unknown matrix or container materials because the engineering assumptions could be wrong. Finally, this 
technology is insensitive to container thicknesses up to $1 / 2$ inch of steel. It can also provide high precision assay measurements irrespective of container geometry.

\section{Regulatory Issues}

In accordance with federal regulations, an exclusion zone was set and periodically monitored around the perimeter of the demonstration site. This ensured no one received more than 2 $\mathrm{mrem} /$ hour for the duration of the test. Actual levels at the exclusion zone were much less than this limit. ${ }^{4}$ An approval letter was also issued by the SRS Health Physics Technology Group allowing Ames Laboratory to bring the $X$-ray tube onsite and'operate it.

\section{Technology Limitations / Needs for Future Development}

The X-ray, K-edge Heavy Metal Detection System was custom designed for the 321-M technology demonstration. Based on lessons learned from the SRS demonstration, Ames Laboratory built an adjustable boom that can easily manipulate an attached inspection head around an object that needs to be assayed. This will minimize job site mobilization costs. Although the inspection head was used to measure uranium in ventilation ducts, the system can also be used to interrogate process pipes and process equipment. Future plans call for making the inspection head components smaller, thereby making the inspection head much lighter and more portable.

\section{Technology Avallability}

Ames Laboratory is currently pursuing commercialization of the X-ray, K-edge Heavy Metal Detection System.

\section{Contacts}

\section{Technical}

Jeffrey Lee, Westinghouse Savannah River Company, (803) 725-0652; jeffreyw.jee@srs.gov Cecil May, Savannah River Technology Center, (803) 725-5813; cecil.may@srs.gov

\section{Management (Department of Energy)}

John Duda, Federal Energy Technology Center, (304) 285-4217, jduda@fetc.doe.gov Martin Salazar, U.S. Department of Energy, Savannah River Operations Office; (803) 557-3617; martin.salazar@srs.gov

George Mishra, U.S. Department of Energy, Savannah River Operations Office; (803)725-7239; george.mishra@srs.gov

\section{Licensing / Vendor}

Terrence Jensen, Center for Nondestructive Evaluation and Ames Laboratory, lowa State University, 515-294-6788; tiensen@cnde.iastate.edu

\section{Web Site}

The 321-M LSDDP Internet address is http://www.srs.gov/general/srtech//std/index.htm

\section{Other}

All published innovative technology summary reports are available online at http:/lem50.em.doe.gov. The Technology Management System, also available through the EM50 web site, provides information about OST programs, technologies, and problems. The OST Reference number for the Portable X-Ray, K-Edge Heavy Metal Detector $@$ is 134. 


\section{SECTION 2}

\section{TECHNOLOGY DESCRIPTION}

\section{Overall Process Definition}

The purpose of the demonstration project's $X$-ray, K-edge characterization technology is to locate, and more accurately quantify, highly enriched uranium (HEU) inside selected $321-M$ Facility ventilation exhaust systems.

Measurements were made at a large number of locations on the rooftop portion of the Lathe Enclosures Exhaust System. This.system provided greater accuracy and better spatial resolution than the baseline approach. The baseline approach is a passive gamma measurement system that utilizes a $\mathrm{Nal}$ (sodium iodide) portable detector.

\section{Hardware}

The X-Ray, K-Edge Heavy Metal Detection System consists of three major subsystems: an Inspection Head, a Control Rack, and a High Voltage \& Cooling Support Cart. ${ }^{2,5,6}$ The X-ray tube and detector module are mounted on a support frame that can be adjusted to accommodate the configuration of the inspected object. The support frame and its attached components is called the inspection head. The control rack includes the computer-controlled data acquisition system

- and a PC monitor. The high voltage/cooling cart provides power to the X-ray tube and the HPGe detector and cooling to the $X$-ray tube. Figure 5 shows a schematic diagram of the $X$-Ray, $K$ Edge Heavy Metal Detection System.

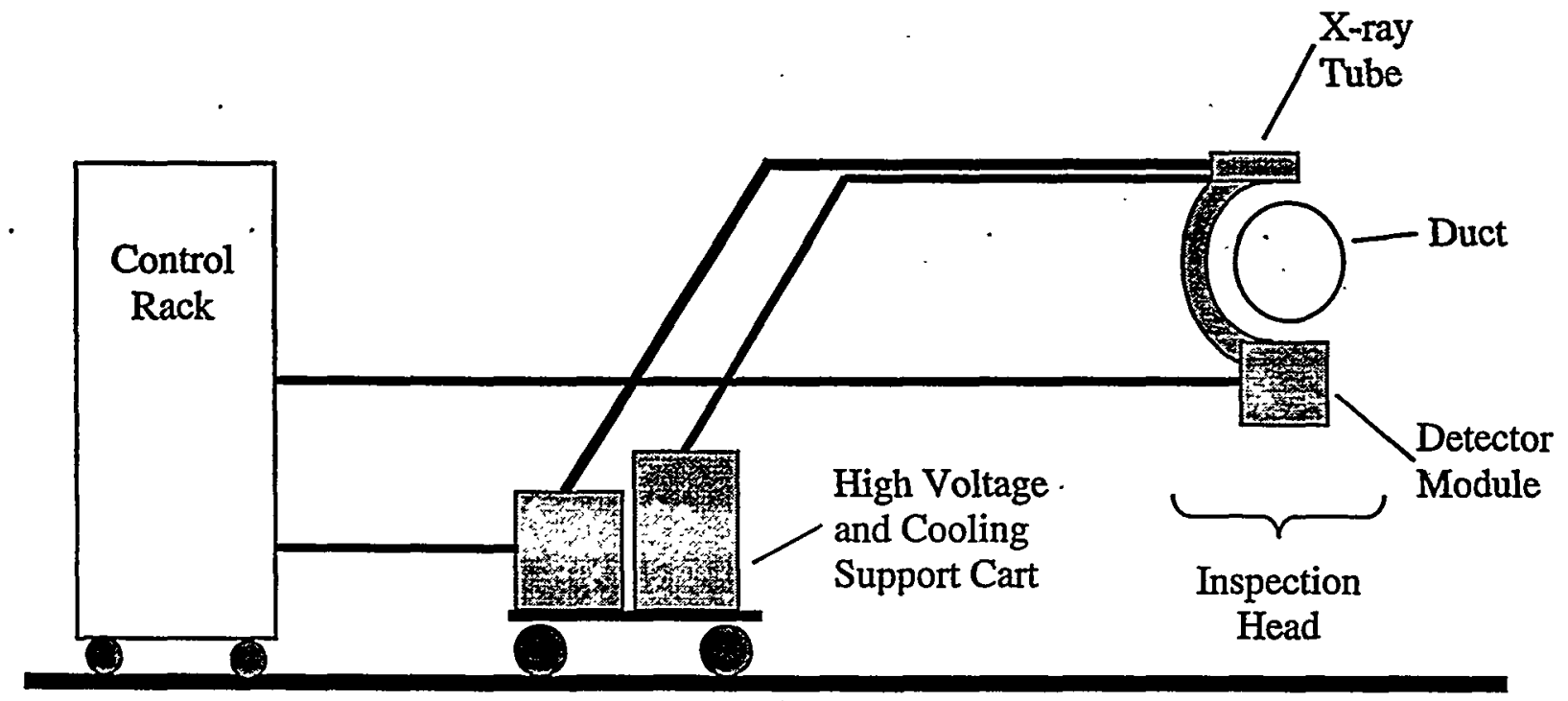

Figure 5. Schematic Diagram of the X-Ray, K-Edge Heavy Metal Detection System

The X-ray, K-edge technology demonstration required Ames Laboratory provide and set up all necessary interconnecting lines and safety interlock components.

- Inspection Head: The inspection head has been customized for $321-M$ ventilation duct use. The COMET MXR $160 \mathrm{kV}, 3 \mathrm{~kW}, \mathrm{X}$-ray tube is mounted on one side of the $\mathrm{C}$-frame (left side of $\mathrm{C}$ - 
frame in Figure 6). A high voltage line and cooling hoses are attached to the $X$-ray tube (visible in Figure 7). To reduce the radiation output of the $X$-ray tube, a tungsten collimator and copper filter are permanently mounted on the beam's output for this demonstration. Additional collimators and filters are installed as necessary to further reduce the $X$-ray tube's radiation output. Opposite the $X$-ray tube and mounted on the other side of the $\mathrm{C}$-frame is the imaging unit and the HPGe (high purity germanium) detector. These components can be laterally shifted to bring them in line with the $X$-ray tube. The imaging unit is a phosphor screen, in a light-tight box, viewed by an intensified CCD camera, interfaced to the control rack computer through a frame-grabber board. The HPGe detector is an EGG\&G ORTEC model GLP-16HCR-S detector. Power, signal, and. control cables link this side of the C-frame to the control rack and the HV cart. The HPGe detector cryostat is filled with liquid nitrogen to cool the germanium crystal to its operating temperature.

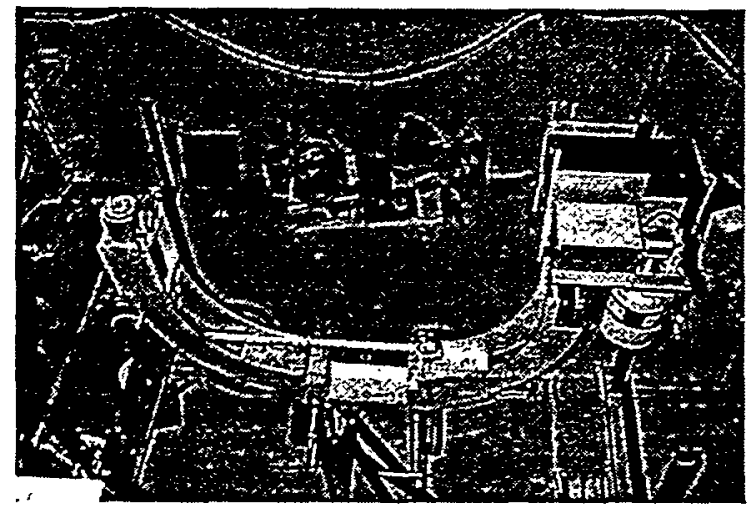

Figure 6. Side View of Inspection Head

The weight of the inspection head is 120 lbs. In the inspection head's "closed" configuration, the opening for a container is 24 inches: In the inspection head's "expanded" mode, the opening is 36 inches. For the demonstration, the inspection head was attached to a vertical stand. The vertical stand, mounted on a dolly, was used to position the inspection head around the exhaust ducts (Fig. 1). The vertical stand was moved over scaffolding platforms to

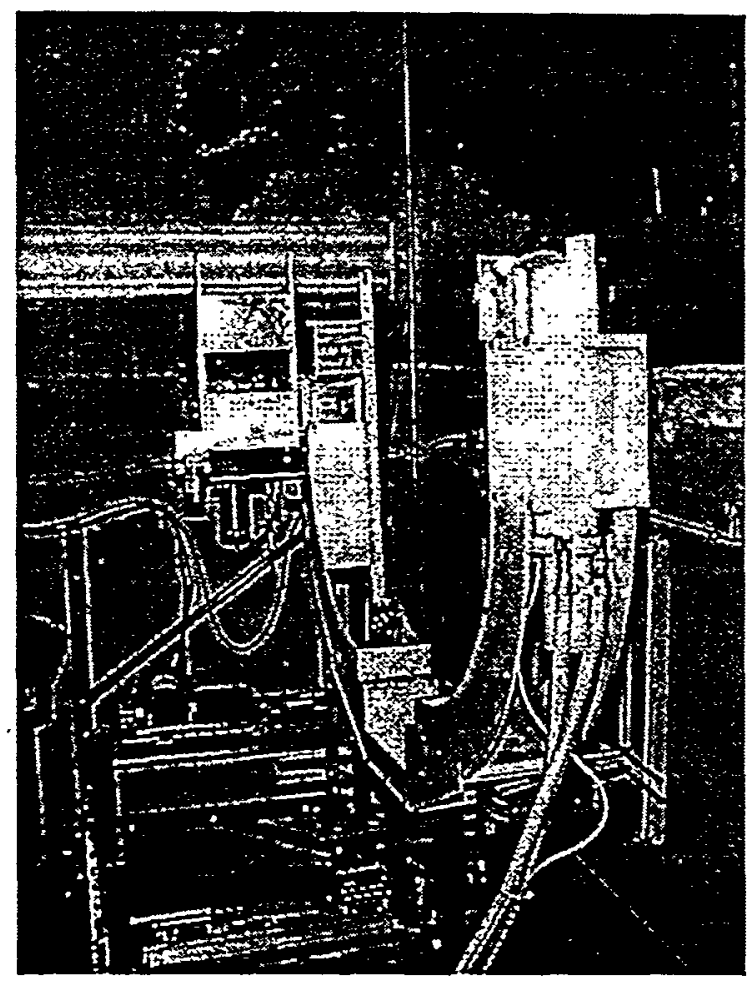

Figure 7. End View of Inspection Head get the inspection head close enough to the exhaust ducts to perform holdup measurements. A wood mock-up of the inspection head was used to facilitate interference identification and determine scaffolding needs. 
- Control Rack: The control rack is where the operator sat during the duration of the demonstration (Fig. 8). A PC monitor on the control rack provided a real-time graph of photon counts versus $X$-ray energy. This display showed the K-edge drop, which could be correlated to a heavy metal concentration. The control rack could be up to 80 feet away from the inspection head (limited by signal and control cables).

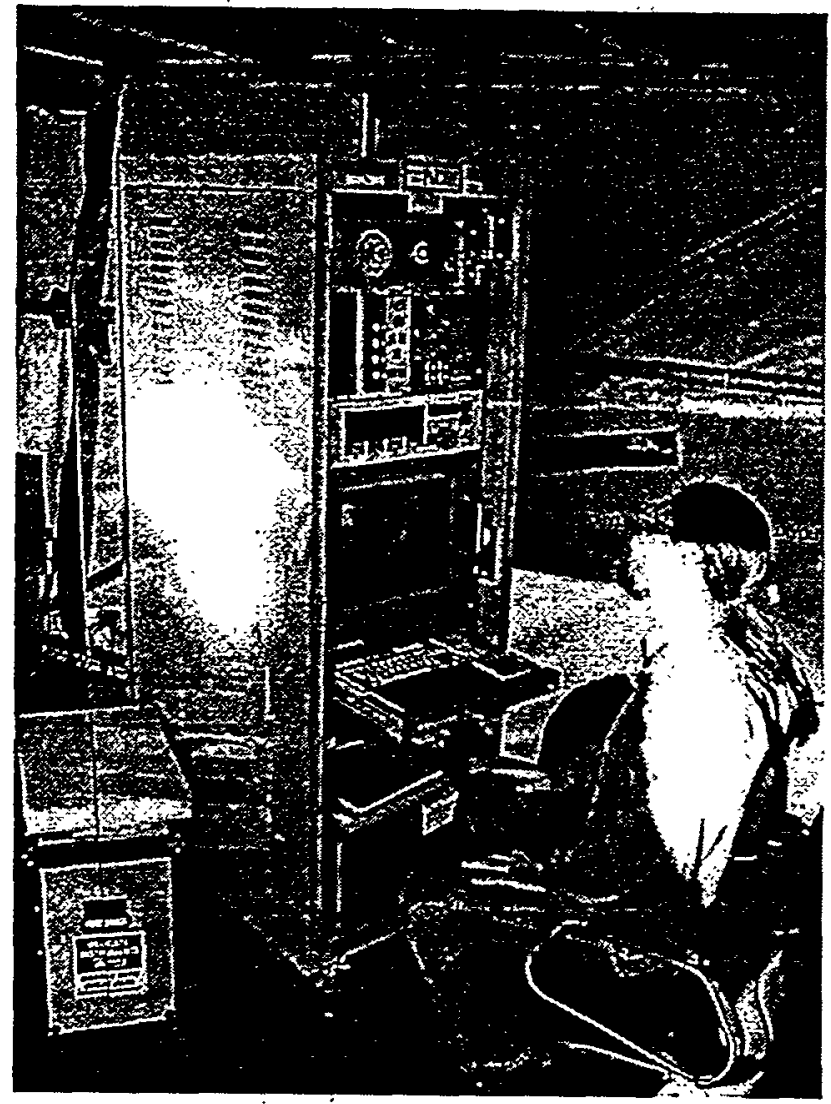

Figure 8: Control Rack

- High Voltage / Cooling Cart: The high voltage unit and the cooling system rest on a moveable platform (Fig. 9). The high voltage unit is on the right and requires a 230 volt power supply. The high voltage unit transformed 230 voits into 160 kilovolts and supplied this high voltage/low current power to the $X$-ray tube.

The cooling system used a Haskris water-to-air cooler. The cooling system provided constant cooling to the $X$-ray tube. The length of the cooling hose and the length of the high voltage power supply line required the HV/cooling cart to be within 60 feet of the inspection head.

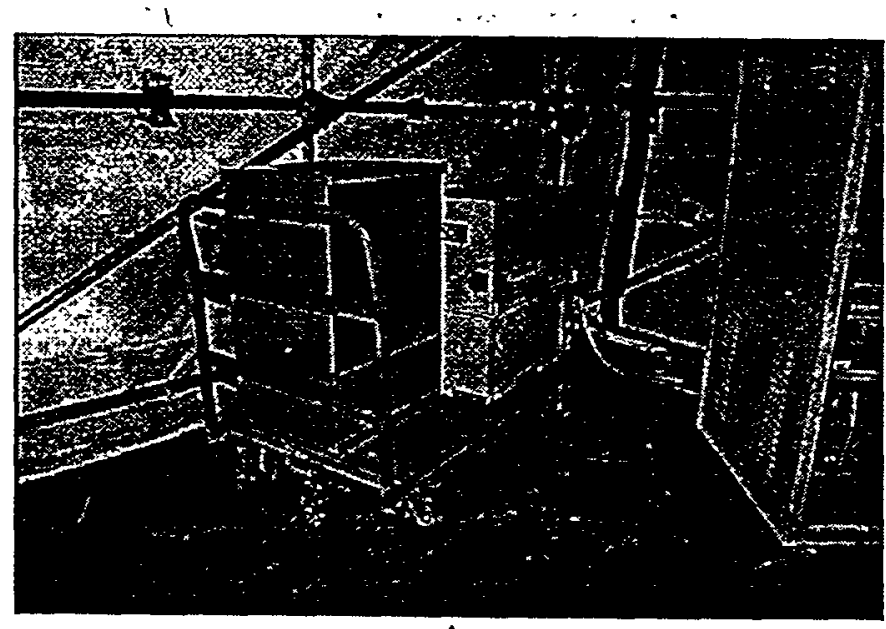

Figure 9. High Voltage/Cooling Cart 


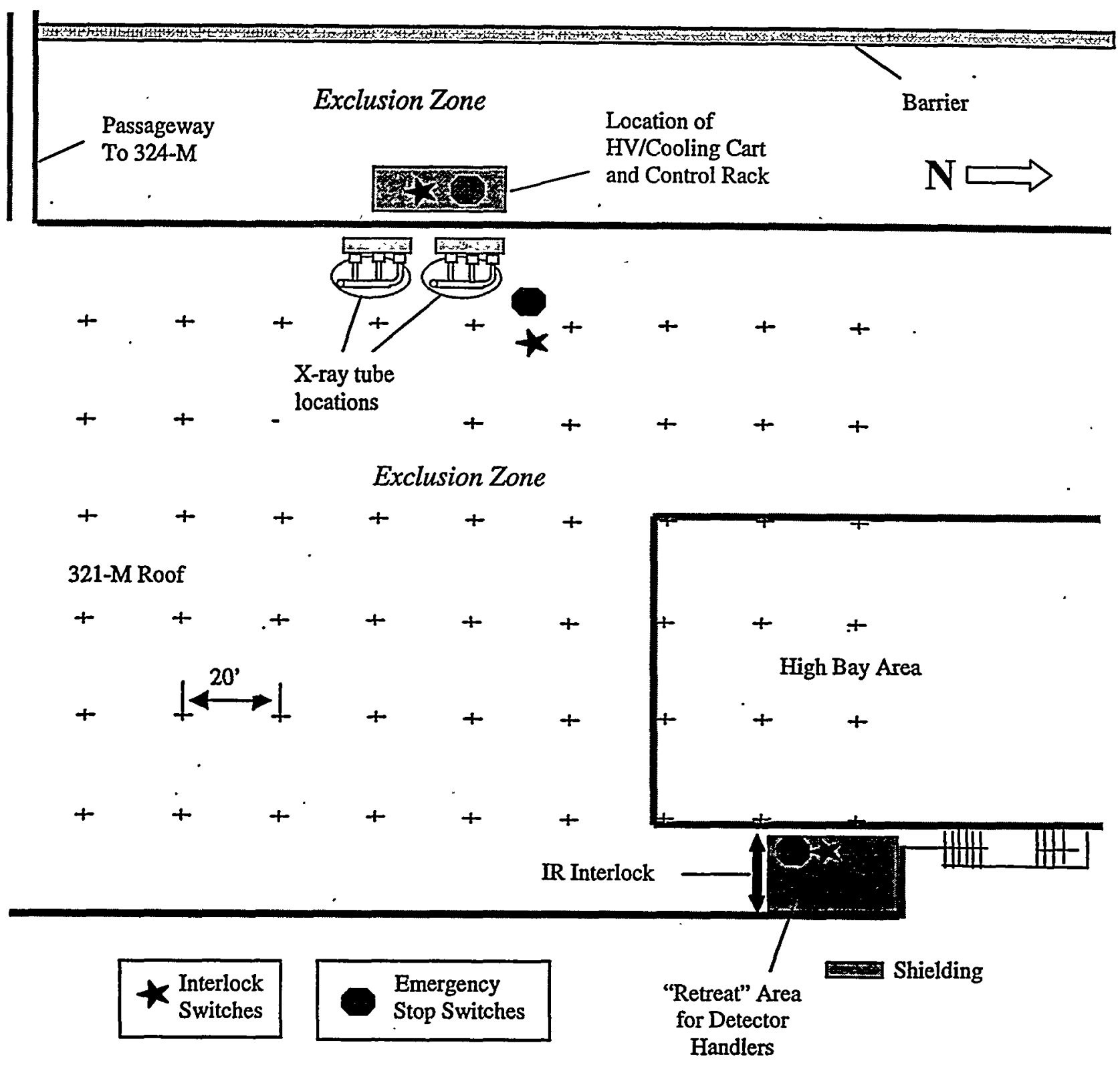

Figure 10. Setup of X-Ray, K-Edge System for 321-M Roof Technology Demonstration

To assure personnel were not inadvertently exposed to excess radiation, Ames Laboratory set up a safety interlock system ${ }^{7}$ as indicated in Figure 10. 
The control rack and the HV/cooling cart were protected from the weather by a plastic hut on the 321M Facility's west wall (Fig. 11). The inspection head could be covered and left on the 321-M roof unless adverse weather made its movement to the nearby 324-M Building advisable.

A source of 230 volt power was provided by an SRS portable generator (Fig. 11).

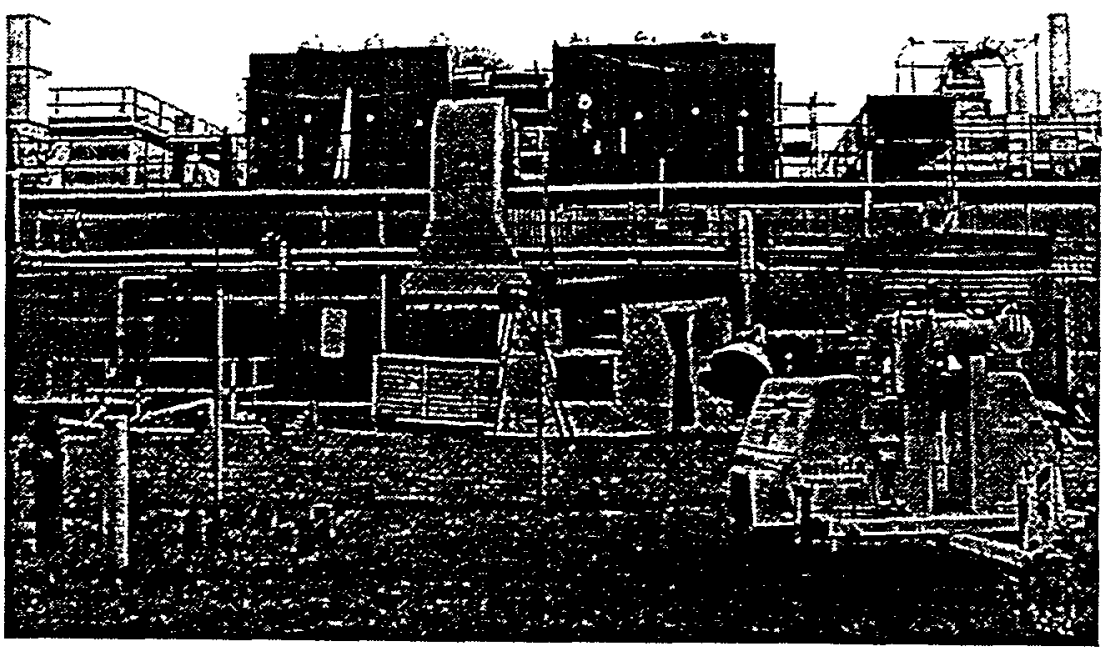

Figure 11. Portable Generator (foreground), Hut and Job Site Shielding (background)

Although the adjustable boom was not ready in time to support the roof demonstration, this device could have minimized, and possibly eliminated, the need for scaffolding. In laboratory tests, the inspection head was coupled to the boom and one operator easily positioned the C. frame around ducts and pipes by using hydraulic and electric motor controls. The operating platform housed the controls and was mobile. The boom arm was designed with 15 feet of reach. See Figure 12

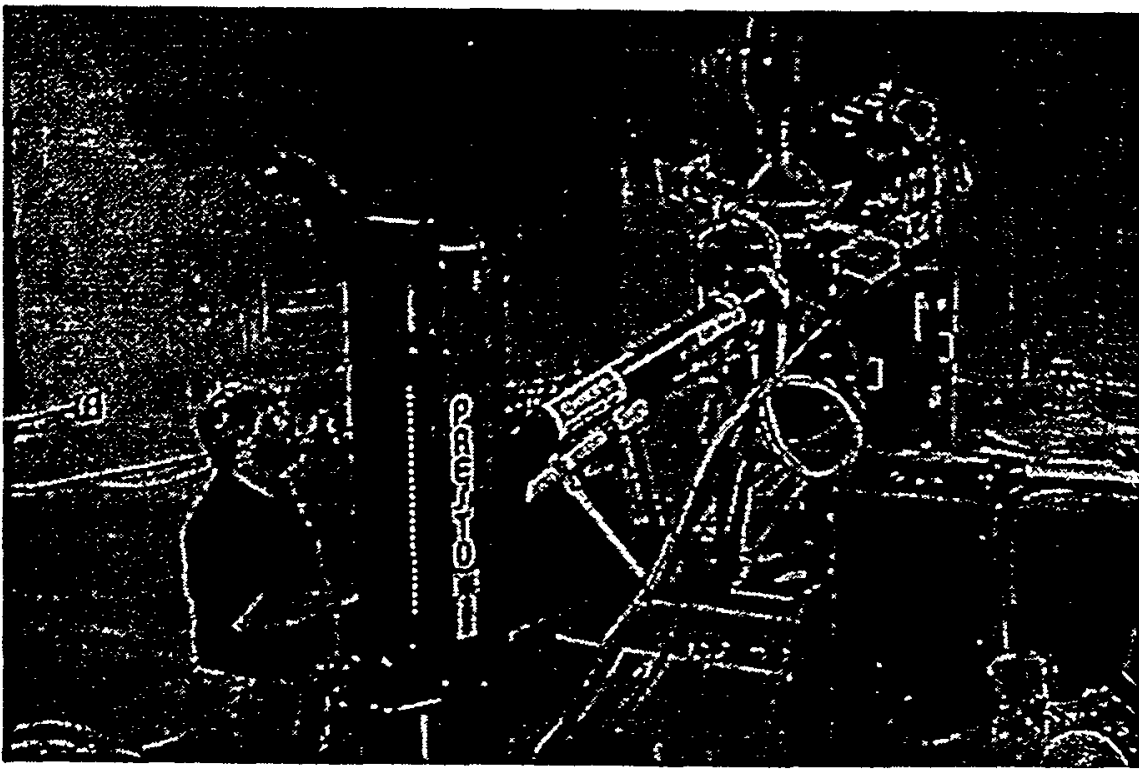

Figure 12. C-Frame Inspection Head at the End of Adjustable Boom 


\section{Princlple of Operation}

X-ray absorption edge densitometers have been used extensively for monitoring nuclear fuel processing operations. ${ }^{8,9}$ These densitometers were optimized to measure several tens of grams per liter of uranium and/or plutonium in solution. However, the technique is quite general and not limited to solutions. ${ }^{10}$

The absorption of photons in materials is governed by the binding energies of atomic electrons. Each element has a unique distribution of electrons, with the K-shell having the highest binding energy. If a photon has just enough energy to liberate one of the K-shell electrons, there will be an increased likelihood that the photon will be absorbed. The rate of absorption can be described by an attenuation coefficient that depends on the $X$-ray energy. If an $X$-ray source having a broad spectrum (such as an industrial $X$-ray tube) is directed through a sample to an energy-sensitive detector on the opposite side, one will observe an abrupt drop in the transmitted intensity at energies corresponding to the K-shell binding energies of elements in the sample. Figure 13 shows a spectrum for a calibration sample consisting of foils of thorium and uranium. The thorium K-edge appears at $109.7 \mathrm{keV}$, while the uranium K-edge appears at $115.6 \mathrm{keV}$. .

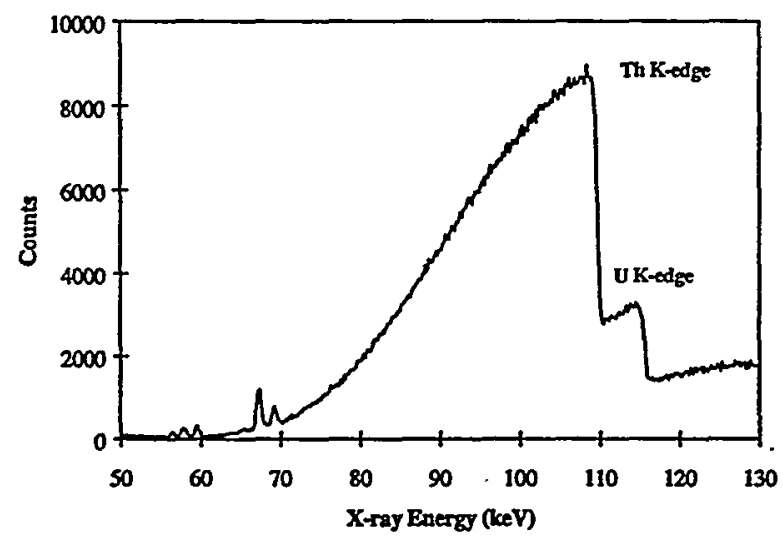

Figure 13. X-Ray Transmission Spectrum for a Sample Consisting of Foils of Thorium and Uranium, Each Approximately 0.25 mm Thick.

The energy at which the abrupt change in transmitted intensity occurs identifies the type of contaminant. The amount of contaminant present can be calculated based on the magnitude of the intensity change. The thickness, $x$, will be given by:

$$
x=\frac{\ln \left[\frac{\mathrm{I}\left(\mathrm{E}_{+}\right)}{\mathrm{I}\left(\mathrm{E}_{-}\right)}\right]}{\mu\left(\mathrm{E}_{-}\right)-\mu\left(\mathrm{E}_{+}\right)}
$$

where $l(E)$, and $I\left(E_{+}\right)$, are the transmitted $X$-ray intensities at energies very close to the edge from the left, and the right, respectively, and $\mu(E)$ and $\mu\left(E_{+}\right)$are the attenuation coefficients of the sample material at these energies. The precision of the $\mathrm{K}$-edge technique is largely insensitive to the thickness or geometry of the container. To a large extent, the measurement uncertainty will be determined by the statistics of the intensity measurements. Typically, a precision of $10 \%$ or better can be achieved within a few minutes measurement time. ${ }^{10}$

The real-time $X$-ray image provides a quick qualitative indication of heavy metal location. The HPGe detector can then be positioned for a spectroscopic shot to accurately quantify the amount

U. S. Department of Energy


of holdup material. In general it will not be feasible to make detailed K-edge measurements covering the entire volume of a sample. Instead, the real-time $X$-ray images are used to determine the non-uniformity of any deposits, and then K-edge measurements are made at selected points and interpolation is done between these measurements to obtain a value for the. total amount of the contaminant. The X-ray, K-edge measurement only provides an elemental analysis of the holdup material. Isotopic information must be calculated. 'To convert the measured uranium values to a specific amount of uranium-235, the measured uranium values are multiplied by the known uranium-235 enrichment fraction. For the Lathe Enclosures Exhaust System case, the enrichment fraction was based on historical information on the materials processed in the facility lathes.

\section{System Operation}

\section{Operational Parameters}

The typical measurement cycle for this demonstration entailed two to eight images and spectroscopic shots per linear foot of ventilation duct. It usually took two minutes to acquire a wide-angle image. It took one to ten minutes to acquire a narrow beam spectra: One minute for the large deposits and upwards of ten minutes to achieve a $99 \%$ confidence level upper limit of approximately one $\mathrm{mg}$ uranium per square centimeter for cases where no obvious deposit was present.

At locations of interest, a wide-angle image and a K-edge spectrum could be acquired without moving the inspection head stand. If the X-ray image provided qualitative confirmation that an interrogated area had significant levels of uranium, several narrow beam spectroscopic shots would be taken. Movement from one location to the next and the resetting of the interlocks, typically took five minutes.

The demonstration team concentrated on the horizontal runs, joints, bends, and transitional pieces of the exhaust ventilation ducts. A grid was marked on the ventilation ducts and each measurement was referenced to this coordinate system.

Additional operating parameters include ${ }^{2}$ :

- High voltage power supply to X-ray tube: Design maximum $-160 \mathrm{kVp}$; normal operation range - 140kVp (1-4 ma)

- High voltage supply to HPGe detector: $2.5 \mathrm{kV}$

- Power supply to HV/Cooling Cart: $230 \mathrm{~V},+10 \%,-15 \%, 30$ amp. $\max$.

- Control Rack power supply: 110V, 20 amp. max.

\section{Operational Concerns/Risks}

- Scattered radiation from X-Ray operations

- Liquid nitrogen will be used to keep the HPGe detector cool.

- High voltage nature of the power supplies requires adequate grounding of system hardware and suspension of $X$-ray activities in the event of heavy rain.

- Scaffolding work

Material, Equipment, and Service Requirements (when specific for 321-M project, marked with *)

- Liquid nitrogen for the HPGe detector cooling reservoir

- Vertical stand \& dolly* (Note: Use the adjustable boom on future jobs.)

- Scaffolding ${ }^{\star}$

- Plastic shelter hut* 
- Temporary shielding*

- Portable lighting*

- Mock-up inspection head ${ }^{*}$

- Electronic pocket dosimeters

- Portable generator (for $\mathbf{2 3 0}$ volt electrical power)*

- 110 volt power from building receptacle

- Crane to move scaffolding and temporary shielding to roof*

\section{Manpower Requirements}

Based on daily logs, 132 readings were taken in 26.5 hours. The demonstration team consisted of the test engineer, two Ames Laboratory scientist/operators, two ironworkers, and two radiological controls $(R C)$ technicians.

The X-ray, K-edge measurements, including all ancillary duties (verifying exclusion zone boundaries, positioning the inspection head, etc.) could have been performed by the two Ames Laboratory representatives. The cost analysis for the $\mathrm{X}$-ray, K-edge field demonstration will only consider time expended by the Ames representatives.

The technology operators are required to be certified in the use of the X-ray generator, must be Radiation Worker II trained, must be trained in the use of a radiation detector, and must have the commensurate educational background and experience to interpret radiographic images and narrow beam spectra.

\section{Other}

Three days of setup time was required before routine operation could begin. This included one day to assemble the equipment and two days to set up and validate radiation shielding and barriers for operation of the X-ray tube. This extended setup time was due to the lack of experience at SRS with this type of.X-ray system. With experience, setup time could be reduced by at least a factor of two.

To minimize the potential for radiation exposure to personnel, $X$-ray operations were conducted during off-normal working hours i.e., the night shift.

High winds and/or heavy rain could have delayed the $X$-ray, K-edge demonstration. Neither occurred during the demonstration window.

For the first day and the last day of the technology demonstration, the average temperature was in the mid 40's. For three nights of the demonstration, during which most of the X-ray, K-edge readings were taken, the average temperature was $32^{\circ} \mathrm{F}$. Although the cold had no effect on the equipment, it did slow down the demonstration team. Warmer weather would have resulted in more measurements.

First time field implementation of the X-ray, K-edge System (other than at Ames Laboratory) resulted in an understandably slow start. As the operators became more familiar with the measurement process, the number of readings per unit time increased. Although the demonstration team was on a steep learning curve, the principals experienced productivity improvements (more readings per unit time) every day they operated the X-ray, K-edge device. 


\section{SECTION 3}

\section{PERFORMANCE}

\section{Demonstration Plan}

\section{Site Description}

For the large scale demonstration of the X-ray, K-edge technology, a subset of equipment/systems at the SRS 321-M Fuel Fabrication Facility was selected. The items targeted for K-edge inspection were exhaust ducts from the two machining lathes. The numerically controlled lathe and the Gisholt lathe are located in the 321-M Machining Room. The numerically controlled lathe is the southern lathe: The Gisholt lathe is the northern lathe. The assay was performed on roof exhaust ducting up to the HEPA filters. Including bends and horizontal runs, 36 feet of 20-inch diameter ventilation duct and 48 feet of 14-inch diameter ventilation duct were surveyed. The ventilation ducts are made of painted, rolled steel approximately $1 / 16$ inch thick. The ventilation duct thickness and geometry presented no problem to the $\mathrm{X}$-ray, K-edge technology. Based on $1995 \mathrm{Nal}$ characterization data, the numerically controlled (NC) lathe rooftop exhaust ducting contains 54.4 grams of highly enriched uranium. The rooftop exhaust system for the Gisholt lathe contains 65 grams of highly enriched uranium. Since 1995 and the Nal survey, the ventilation fans for this system have been in almost constant operation. Some HEU movement inside the exhaust ducts is suspected.

\section{Performance Objectives}

The main objective of the X-Ray, K-Edge.technology demonstration was to determine the type and amount of holdup material in the roof portion of the Lathe Enclosures Exhaust System. This investigation assessed the X-Ray, K-Edge Heavy Metal Detection System based on its performance in achieving the following demonstration objectives:

- improved accuracy in quantifying holdup material to facilitate the resolution of criticality, safeguards and security, and material control \& accountability issues

- provision of a profile of contaminants inside the surveyed ventilation duct that will better prepare the project team for making cost effective decisions on future ventilation duct $D \& D$ work.

\section{Results}

Only the horizontal runs of the exhaust system were inspected, as this is where the holdup material is expected to be located. The typical measurement cycle for this demonstration entailed two to eight images and spectroscopic shots per linear foot of ventilation duct. An example image and associated spectrum are shown in Figure 14. In the image, darker regions correspond to areas where the duct wall is thicker, or where there is holdup material. The image shows a variation in density, and filaments of the type expected from lathe machining can be distinguished. The corresponding spectrum shows a strong signal for uranium.

When the images clearly showed the presence of uranium, three to six (narrow beam) interrogative shots were made to verify the element and quantify the deposit. Larger deposits only required a one to two-minute count time to obtain measurements with a precision in the $\pm 3 \%$ range. In cases where there was no obvious indication of uranium, it could take up to ten minutes to achieve a $99 \%$ confidence level upper limit of approximately one $\mathrm{mg}$ uranium per square $\mathrm{cm}$.

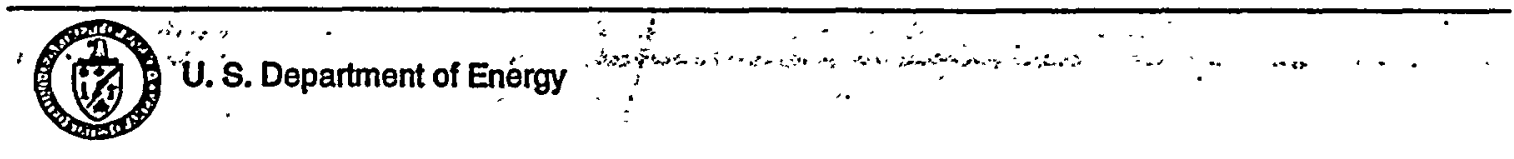



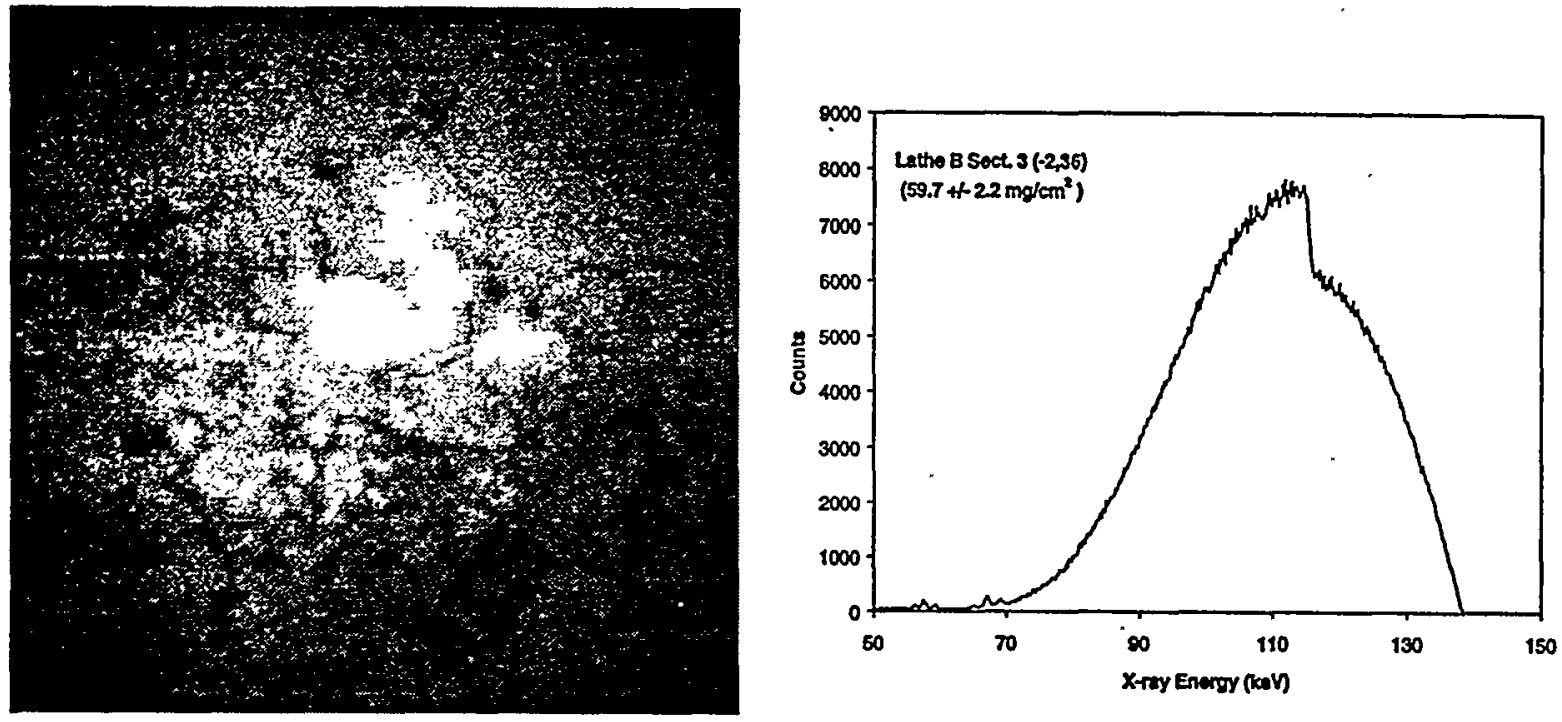

Figure 14. Real-time X-ray image $(12 \mathrm{~cm} \times 12 \mathrm{~cm})$ and associated $\mathrm{K}$-edge spectrum obtained for one location on the ducts. The darker regions in the image correspond to the location of holdup material. The spectrum was acquired at a point near the center of the image.

The system was operated for a total of 26.5 hours over a five-day period. During this time wide angle images and narrow beam spectra were acquired at 66 locations on the ducts (system testing and calibration was included in this time).

To obtain the total amount of uranium holdup in a region, a calibration was performed to relate the image density (in gray scale units ranging from 0 to 255) to the uranium density (in $\mathrm{mg} / \mathrm{cm}^{2}$ ), and a sum was formed over the pixels in the image, applying the length scale for the image. Each image covered approximately a $12 \mathrm{~cm}$ by $12 \mathrm{~cm}$ region of the duct. The total uranium holdup in a section was obtained by adding the contributions from all images obtained for that section. To convert these results to an amount of U-235 holdup, the K-edge numbers must be multiplied by the enrichment fraction for the alloy mixture. For the lathe exhaust ducts, an enrichment of $70 \% \mathrm{U}-235$ was deduced from historical information on the materials processed by the lathes. ${ }^{3,11}$

The K-edge results are displayed in Figures 15 and 16 for each section of the ductwork. The uncertainties in these measurements are dominated on the low side by uncertainty in the conversion from image density to uranium density, and on the high side by the limit in sensitivity to small amounts of uranium spread over a large area. For those cases where no significant indication of uranium was found in a section of duct, an upper limit on the holdup at a $95 \%$ confidence level is indicated. Those cases with relatively large uncertainties or upper limits are regions where few measurements were made. If the calculations are done for smaller regions where multiple measurements were made, the precision will improve.

The results for the baseline passive-gamma NDA measurements are also shown in Figures 15 and 16. They are in agreement with the K-edge results, but the K-edge measurements yield much better spatial information. For both exhaust systems, the HEU holdup. was found to be concentrated around the joint between sections 3 and 4 . Measurements made with a radiation survey meter (Bicron $\mu$ rem meter) confirmed these findings (see Figs. 15 and 16). Also, from the $X$-ray images, the nature of the holdup material was determined. In the lathe $A$ ducts, the material was seen to be primarily dust, whereas, in the lathe B ducts the material was mostly in the form of lathe turnings and small chips. 

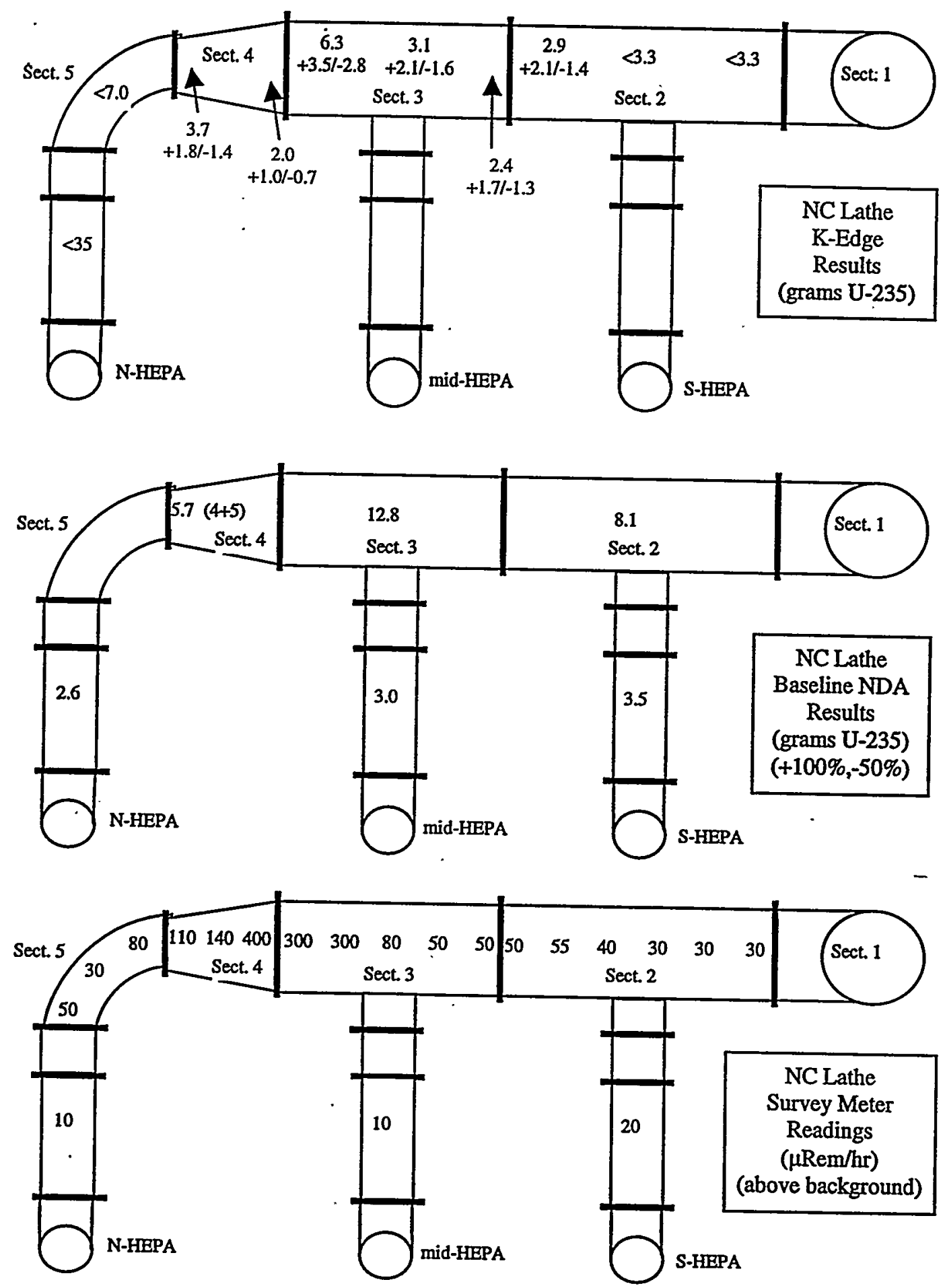

Figure 15. Comparison of results from K-edge measurements with baseline NDA measurements and survey meter readings for the NC Lathe ducts. 

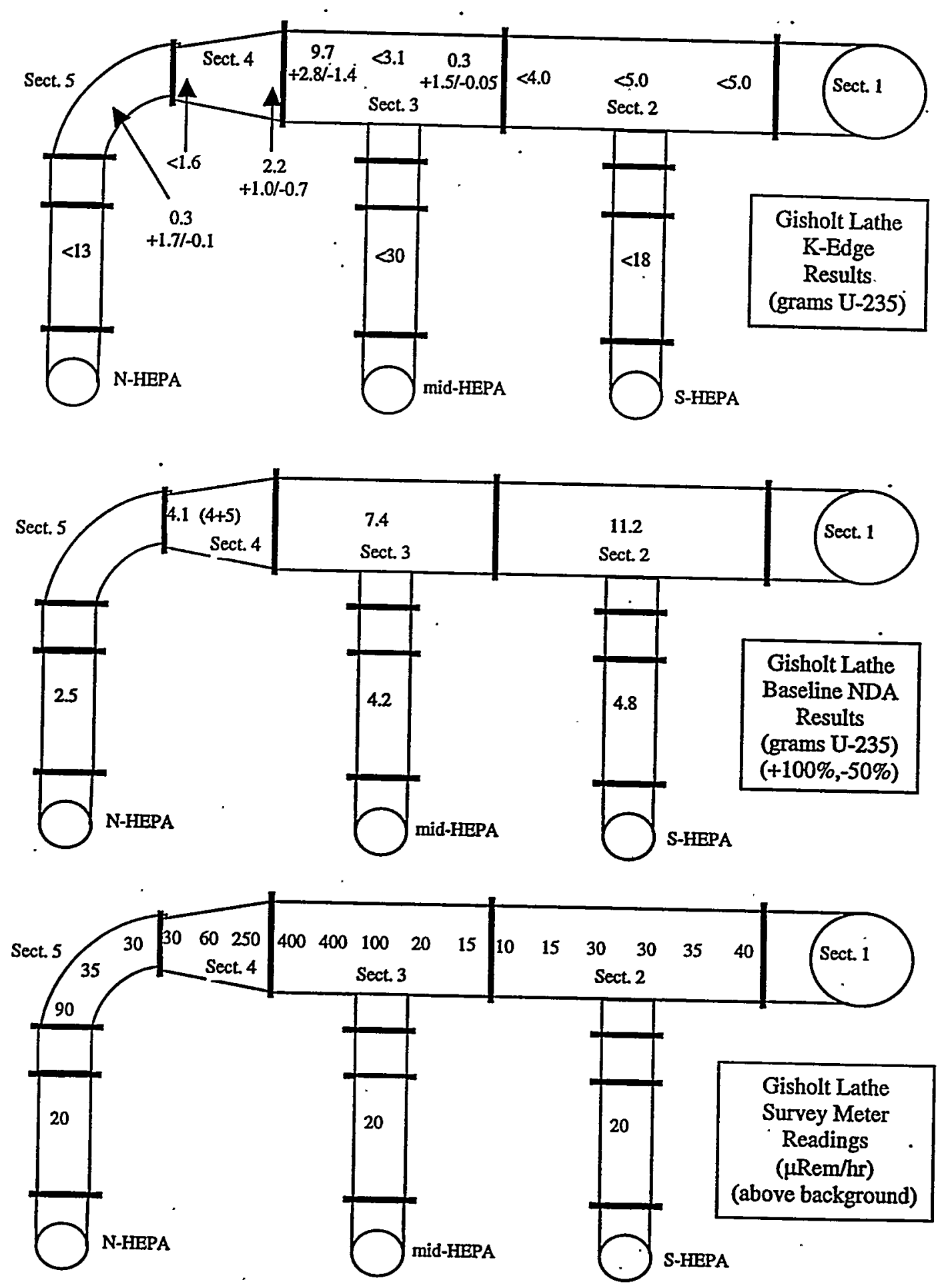

Figure 16. Comparison of results from K-edge measurements with baseline NDA measurements and survey meter readings for the Gisholt Lathe ducts. 
Since comprehensive K-edge measurements were not made on the vertical exhaust duct runs nor on the 10-inch horizontal runs and bends upstream of the HEPA filters, the demonstration team decided not to report individual exhaust system grand totals for the NC exhaust system and the Gisholt exhaust system. However, a quick analysis of the data depicted in Figures 15 and 16 reveals K-edge sums approximately $2 / 3$ that of the $1995 \mathrm{Nal}$ totals.

The K-edge measurements also indicate that most of the HEU holdup is located in duct sections 3 and 4 , whereas the baseline measurement found significant holdup in section 2 as well. As the exhaust fans have been operated since 1995 when the baseline survey was performed, it is possible that some of the holdup material has moved downstream (toward sections 3 and 4). To test this hypothesis, it is planned to make new baseline Nal measurements. 


\section{SECTION 4}

\section{TECHNOLOGY APPLICABILITY AND ALTERNATIVES}

\section{Competing Technologies}

The baseline technology for measuring HEU holdup in ducts, pipes and equipment is a passive gamma survey using a hand-held $\mathrm{Nal}$ detector. Other gamma detectors, such as a high purity germanium detector could also be used for this type of measurement. This technology is well established and used extensively in measuring holdup of radioactive materials. Other competing technologies ${ }^{8}$ include passive neutron survey, neutron activation analysis, X-ray fluorescence, and invasive sampling.

A Passive neutron survey can be effective for larger quantities of fissionable material. Neutron activation analysis has routinely been used for samples that could be brought to a high-flux nuclear reactor. Due to the difficulty in producing a high-flux portable neutron source, in situ application of this technology has been limited. X-ray fluorescence analysis is a standard technology used primarily for analysis of surfaces and carefully prepared samples. Because of the hazards associated with invasive sampling of holdup material, this technique is a method of last resort. A comparison of each of these technologies with the X-ray K-edge technology is presented in Table 1 below.

Table 1. Comparison of the innovative X-ray K-edge technology with the baseline passive gamma technology and other competing technologies.

\begin{tabular}{|c|c|c|}
\hline Technology & Adyantages: & Disadvantages \\
\hline X-ray K-edge . & $\begin{array}{l}\text { - Noninvasive } \\
\text { - Insensitive to container geometry } \\
\text { and material } \\
\text { - Provides very good information on } \\
\text { spatial distribution of holdup } \\
\text { material. } \\
\text { - Can operate in high background } \\
\text { radiation field. }\end{array}$ & $\begin{array}{l}\text { - Somewhat bulky and difficult to } \\
\text { maneuver in tight locations. } \\
\text { - Requires access to both sides of } \\
\text { object being inspected. } \\
\text { - Cannot distinguish between } \\
\text { different isotopes of an element. } \\
\text { - Personnel must be a safe distance } \\
\text { away from the X-ray source while it } \\
\text { is active. }\end{array}$ \\
\hline $\begin{array}{l}\text { Passive Gamma } \\
\text { (baseline) }\end{array}$ & $\begin{array}{l}\text { - Noninvasive } \\
\text { - Nal detector is highly portable. } \\
\text { HPGe detector is fairly portable. } \\
\text { Provides good information on } \\
\text { isotopic composition of holdup } \\
\text { material. }\end{array}$ & $\begin{array}{l}\text { Results are sensitive to corrections } \\
\text { for absorption in container walls. } \\
\text { - Results depend on assumptions } \\
\text { about distribution of holdup } \\
\text { material. } \\
\text { - Limited spatial resolution. } \\
\text { - High background radiation fields } \\
\text { can corrupt data. }\end{array}$ \\
\hline Passive Neutron & $\begin{array}{l}\text { Noninvasive } \\
\text { - Thick-walled containers can be } \\
\text { surveyed }\end{array}$ & $\begin{array}{l}\text { Prior knowledge of chemical form } \\
\text { and isotopic composition is } \\
\text { required. } \\
\text { - Results depend on assumptions } \\
\text { about distribution of holdup } \\
\text { materials. }\end{array}$ \\
\hline
\end{tabular}




\begin{tabular}{|c|c|c|}
\hline Techiológ, & Advantages & Disadvantáges \\
\hline $\begin{array}{l}\text { Neutron } \\
\text { Activation }\end{array}$ & $\begin{array}{l}\text { Noninvasive } \\
\text { - Can penetrate relatively thick } \\
\text { containers. }\end{array}$ & $\begin{array}{l}\text { - Results are sensitive to corrections } \\
\text { for absorption in container walls. } \\
\text { - Results depend on assumptions } \\
\text { about distribution of holdup } \\
\text { material. } \\
\text { - Personnel must be a safe distance } \\
\text { away from the neutron source } \\
\text { while it is active. }\end{array}$ \\
\hline $\begin{array}{l}\text { X-ray } \\
\text { Fluorescence }\end{array}$ & $\begin{array}{l}\text { Noninvasive } \\
\text { Good sensitivity. }\end{array}$ & $\begin{array}{l}\text { Results are dependent on } \\
\text { corrections for absorption in } \\
\text { container walls. } \\
\text { - Cannot distinguish between } \\
\text { different isotopes of an element. } \\
\text { - Personnel must be a safe distance } \\
\text { away from the x-ray source while it } \\
\text { is active. }\end{array}$ \\
\hline $\begin{array}{l}\text { Invasive } \\
\text { Sampling }\end{array}$ & $\begin{array}{l}\text { - Very accurate determination of } \\
\text { sample material composition }\end{array}$ & $\begin{array}{l}\text { - Sample may not be representative } \\
\text { of whole object. } \\
\text { - Risk of contaminating personnel } \\
\text { and equipment when obtaining } \\
\text { sample. } \\
\text { - Samples and associated } \\
\text { containers must be disposed of as } \\
\text { waste when analysis is completed. }\end{array}$ \\
\hline
\end{tabular}

\section{Technology Applicability}

The X-ray, Kedge Heavy Metal Detection System was used to locate and quantify highly enriched uranium in 321-M ventilation exhaust ducts. Other potential applications exist. Criteria used to select this technology over a baseline characterization method include the following:

- Need for Precision: Benefits realized when assay performed to determine criticality potential, in response to safeguards \& security issues, and to meet material control \& accountability requirements.

- Size of Job: The larger the job, the more the higher mobilization costs for the X-ray, K-edge - deployment can be spread out over the entire job, and the lower the unit production costs will be.

- Insensitivity to Container Material, Thickness and Geometry: Within the limits of $X$-ray penetrability, X-ray, K-edge is unaffected by the container material, the container thickness, and the container geometry. Passive gamma measurements must allow (via engineering assumptions) for all three parameters.

- Insensitivity to High Background Radiation Fields: As the background radiation field increases, $X$-ray, $K$-edge becomes a more accurate altemative to passive gamma measurements.

- Need to Distinguish Between Containers in Close Proximity to One Another: For example, two process pipes located next to each other - one with uranium in it, one clean. The X-ray, K-edge device could identify the clogged pipe, the material clogging the pipe, and how much of the material is present. An arm's length passive gamma measurement would have trouble identifying the clogged pipe, could not precisely predict the material profile inside the pipe, and could not accurately quantify the amount of holdup material inside the pipe. 
The X-ray, K-edge heavy metal detector can locate and profile a number of elements: uranium, plutonium, lead, mercury, thorium, etc. Ventilation ducting, process piping, and process equipment are three examples of containers that can be interrogated by the X-ray, K-edge detector. Waste drums and waste boxes could also be assayed by this technology.

The X-ray, K-edge Heavy Metal Detection System that was demonstrated at the SRS 321-M Fuel Fabrication Facility used a $160 \mathrm{kV}, 3 \mathrm{~kW}, \mathrm{X}$-ray tube. Adjusting the $\mathrm{X}$-ray generator current setting (which will directly increase the $X$-ray flux) will allow one to see through thicker material. Utilizing a higher potential $X$-ray generator $(320 \mathrm{kV}$ versus $160 \mathrm{kV})$ will also provide some improvement in $X$-ray penetrating capabilities.

The C-frame opening accommodates items up to 36 inches in diameter. This frame was custom designed for the 321-M Large Scale Demonstration and Deployment Project. Larger openings could be easily designed into the $\mathrm{C}$-frame.

The size and weight of the inspection head is being reduced to make future in-situ applications easier.

The adjustable boom can place the C-frame inspection head around objects 15 feet above the floor. A longer boom (with a lighter inspection head) could be designed that would reach further into the overhead.

A computer program is being developed that will analyze a 5 -inch square $X$-ray image, count the gray scale computer image pixels, and provide the operator with a real-time estimate of the heavy metal coverage. This value, multiplied by the measured spectroscopic thickness, allows the operator to instantly quantify the amount of heavy metal in the 5-inch window.

\section{Patents/Commercialization/Sponsor}

The Center for Nondestructive Evaluation and Ames Laboratory at lowa State University have not applied for a patent for the X-Ray, K-Edge Heavy Metal Detection System.

The computer software program used to control $X$-ray, K-edge data acquisition and real-time data analysis is available under a license agreement from Ames Laboratory.

Ames Laboratory has had discussions with several radiation survey instrument companies on the potential commercialization of the X-Ray, K-Edge System. There has also been some interest expressed by the researchers in starting a small company that would market the X-Ray, K-edge technology as a service.

The Office of Science and Technology (EM-50) has sponsored the X-ray, K-edge work for several years. The Characterization, Monitoring, and Sensor Technology (CMST) Focus Area and the D\&D Focus Area were the prime champions of this technology. 


\section{SECTION 5}

\section{$\cos T$}

\section{Introduction/Methodology}

This cost analysis compares the innovative Portable X-Ray, K-Edge Heavy Metal Detector technology with the baseline $\mathrm{Nal}$ handheld detection system. The objective of the analysis is to assist decision makers who are debating whether further investigation of $X$-ray, $K$-edge technology is warranted. A subcontracted vendor (Ames Laboratory) demonstrated the innovative technology. Site forces performed the baseline technology. Both technologies assayed ventilation ducting on the roof of the 321-M Fuel Fabrication Facility.

This analysis strives to develop realistic estimates that represent actual characterization work within the U.S. Department of Energy at the Savannah River Site. It is a limited representation of actual cost because some of the observed costs were adjusted or eliminated to allow for first-time use inefficiencies and bureaucratic red tape. These adjustments were allowed if they would not distort the fundamental elements of the observed data (i.e., the adjustments would not change productivity rates, amounts surveyed, etc.). In addition, only those activities which were atypical of normal characterization work were eliminated.

Cost and performance data was collected for both the innovative and baseline technologies. The following cost elements were identified from the Army Corps of Engineers (ACOE) Hazardous, Toxic and Radioactive Waste Remedial Action Work Breakdown Structure and Data Dictionary (HTRW RA WBS):

- Mobilization

- Characterization

- Demobilization

Mobilization costs include the cost of transporting the technology equipment to the site, meeting administrative requirements prior to commencing field work, preparation of the temporary work area (including equipment setup), and installation of temporary utilities.

Characterization includes all direct and indirect activities associated with performing assay measurements. Calibration checks, safety interlock checks, alignment checks, assay measurements, equipment repositioning, and troubleshooting are a few of the activities that fall under the characterization umbrella. The recording, collection, and presentation of the assay data are also included in this cost element.

Demobilization includes the breakdown of technology equipment and packaging of that equipment for shipment, removal of temporary utilities, and return of the work site to a preestablished condition.

Personal protective equipment (PPE) costs were not included in this demonstration. The areas assayed were not contaminated and did not require PPEs. Vendor training and badging preparations was not considered. The time required to fulfill most of the internal management review prerequisites was not considered. 


\section{Cost Analysis}

Data was collected during the performance of the baseline technology and the demonstration of the innovative technology. Time to complete a job was recorded. Labor hours were multiplied by the respective worker's charge rate. As applicable, equipment and material cost was added to the labor cost. Unit costs were determined based on the linear feet of duct work assayed and the number of assay measurements. Assay measurements were also known as Nal shots or X-Ray, K-Edge shots.

Site labor rates used in the analysis were those in effect for the SRS site labor agreement and vendor contract rates were agreed to with Ames Laboratory in Contract AC02466V. Crews for the various activities were based on the data collected. Crew size was modified as necessary to make the demonstration reflect a true commercial effort. Time for personnel supporting the demonstration aspects of the activity (oversight, data recording, etc.) was not included in the labor cost subtotais. Individual charge rates covered the worker's salary and benefits: Site overheads were omitted from the analysis. Quality assurance and taxes were omitted from the analysis.

$X-R a y, K-E d g e$ equipment costs were based on the cost of ownership. The cost of the X-Ray, KEdge Heavy Metal Detection System is $\$ 126,000$ without the adjustable boom and $\$ 139,500$ with the adjustable boom. Individual pieces of equipment in the X-Ray, K-Edge System have expected lifetimes ranging from 5000 hours to 20,000 hours of operation. The equipment's extended cost per hour of use is estimated to be $\$ 25 /$ hour and is based on the anticipated life span of the equipment. The $\$ 25 /$ hour equipment rate applies to both cases - the X-Ray, K-Edge package without the adjustable boom and with the adjustable boom.

The adjustable boom was not used to perform a ventilation duct survey on the roof of the 321-M Facility. It became available after the rooftop portion of the demonstration was complete and was scheduled to be used in the 321-M Contamination Area (CA). Project funding constraints resulted in the eventual cancellation of the X-Ray, K-Edge CA job. If the adjustable boom would have been used in the CA, it could have eliminated the need for scaffolding and the vertical stand. This same advantage could have been realized on the $321-\mathrm{M}$ roof if the boom had been ready for this portion of the demonstration. Based on laboratory tests in Ames, lowa and discussions with the technology vendor representatives, the X-Ray, K-Edge System with the adjustable boom should be able to perform the same number of measurements in $20 \%$ less time. ${ }^{12}$ This $20 \%$ reduction was applied to empirical labor data for the without boom case. The tables below reflect this advantage.

The Nal equipment rate was based on the following assumptions: (1) The cost of the Nal detector and multi-channel analyzer is $\$ 12,000$. (2) The expected useful life of the $\mathrm{Nal}$ detector and multi-channel analyzer is 8-10 years. Eight years was assumed for the equipment rate calculation. (3) The equipment was assumed to operate 8 hours per week, for 50 weeks per year. The equipment's extended cost per hour of use is estimated to be $\$ 3.75 /$ hour and is based on the anticipated life span of the equipment.

For fixed cost activities (i.e.; Mobilization and Demobilization activities) that are independent of the quantity of characterization work, costs were calculated as lump sum costs instead of unit costs. These lump sum costs were expressed on the basis of the job (e.g., the assay of the 321$M$ rooftop ventilation duct). Unit costs were dependent on the quantity of characterization work. Unit costs for both the baseline technology and the innovative technology were expressed on the basis of linear feet of ventilation duct assayed as well as assay measurements or shots per job.

A comparison of unit costs for the Characterization cost element is shown in Tables 2 and 3. This summary unit cost comparison is provided for two innovative technology cases and the baseline technology case. Unit costs are expressed in both $\$ \Omega F$ and $\$ /$ shot. Production rates are 
expressed in LF/hour and shots/hour. Table 4 captures the Mobilization and Demobilization costs for performance of the baseline technology and demonstration of the innovative technology. These costs are fixed costs and independent of the amount of characterization work. These costs were used to perform a break-even analysis. .

Table 2. Summary Unit Cost Comparison

(Innovative Technology without Boom Case)

\begin{tabular}{|c|c|c|c|c|c|}
\hline 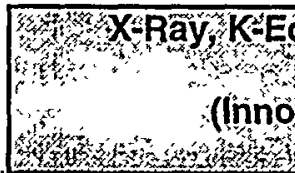 & 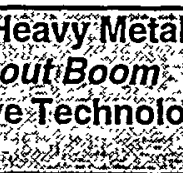 & (y) & 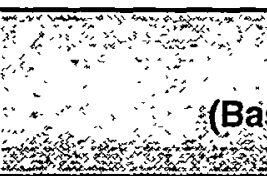 & Nâl & \\
\hline Cost Element & Unit Cost & $\begin{array}{l}\text { Production } \\
\text { Rate }\end{array}$ & Cost Element & Unit Cost & $\begin{array}{l}\text { Production } \\
\text { Rate }\end{array}$ \\
\hline $\begin{array}{l}\text { Characterization } \\
\text { (LF basis) }\end{array}$ & $\$ 48.58 / \mathrm{LF}$ & $2.18 \mathrm{LF} / \mathrm{hr}$ & $\begin{array}{l}\text { Characterization } \\
\text { (LF basis) }\end{array}$ & $\$ 47.48 / \mathrm{LF}$ & $2.29 \mathrm{LF} / \mathrm{hr}$ \\
\hline $\begin{array}{l}\text { Characterization } \\
\text { (shot basis) }\end{array}$ & $\$ 30.91 /$ shot & 3.43 shots $/ \mathrm{hr}$ & $\begin{array}{l}\text { Characterization } \\
\text { (shot basis) }\end{array}$ & \$110.78/shot & .98 shots $/ \mathrm{hr}$ \\
\hline
\end{tabular}

Table 3. Summary Unit Cost Comparison (Innovative Technology with Boom Case)

\begin{tabular}{|c|c|c|c|c|c|}
\hline \multicolumn{3}{|c|}{ 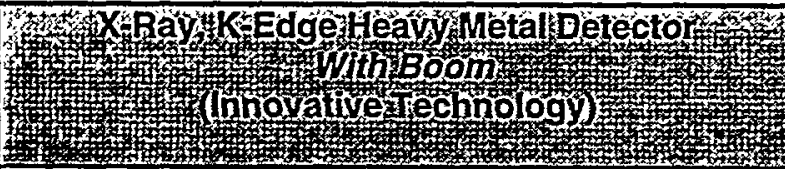 } & \multicolumn{3}{|c|}{ 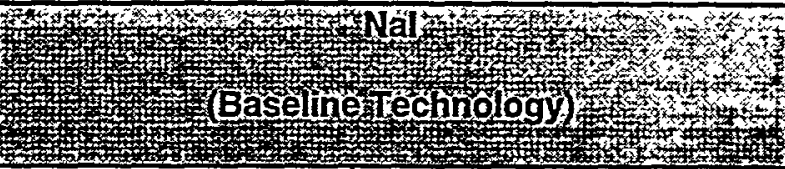 } \\
\hline Cost Element & Unit Cost & $\begin{array}{l}\text { Production } \\
\text { Rate } \\
\end{array}$ & Cost Element & Unit Cost & $\begin{array}{l}\text { Production } \\
\text { Rate }\end{array}$ \\
\hline $\begin{array}{l}\text { Characterization } \\
\text { (LF basis) }\end{array}$ & $\$ 40.39 \pi \mathrm{F}$ & $2.55 \mathrm{LF} / \mathrm{hr}$ & $\begin{array}{l}\text { Characterization } \\
\text { (LF basis) }\end{array}$ & $\$ 47.48 / \mathrm{LF}$ & $2.29 \mathrm{LF} / \mathrm{hr}$ \\
\hline $\begin{array}{l}\text { Characterization } \\
\text { (shot basis) }\end{array}$ & \$25.70/shot & 4.00 shots $/ \mathrm{hr}$ & $\begin{array}{l}\text { Characterization } \\
\text { (shot basis) }\end{array}$ & $\$ 110.78 /$ shot & .98 shots/hr \\
\hline
\end{tabular}

Table 4. Fixed Costs

\begin{tabular}{|c|c|c|c|}
\hline 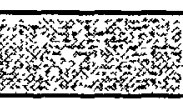 & Mópilization & Depobilization & 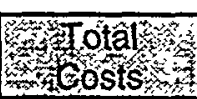 \\
\hline Baseline & $\$ 400$ & $\$ 0.00$ & $\$ 400$ \\
\hline $\begin{array}{l}\text { Innovative } \\
\text { (wthout boom) }\end{array}$ & $\$ 57,978$ & $\$ 8,210$ & $\$ 66,188$ \\
\hline $\begin{array}{l}\text { Innovative } \\
\text { (uthth boom) }\end{array}$ & $\$ 37,619$ & $\$ 5,937$ & $\$ 43,556$ \\
\hline
\end{tabular}

A break-even analysis was performed using data in Tables 2, 3, and 4. Since unit costs for the $X$ Ray, K-Edge System without the boom were higher than that for the baseline Nal System, a 
break-even point would never be reached for this scenario. Figure 17 depicts the break-even point if the X-Ray, K-Edge System with the boom was used for the comparison. For this case, the break-even point occurs at 6087 linear feet of ducting. Several first time mobilization costs for preparation of a worker protection plan, radiation shielding calculations, and development of a standard operating procedure would be expected to be greatly reduced for future deployments. This would push the break-even point significantly lower.

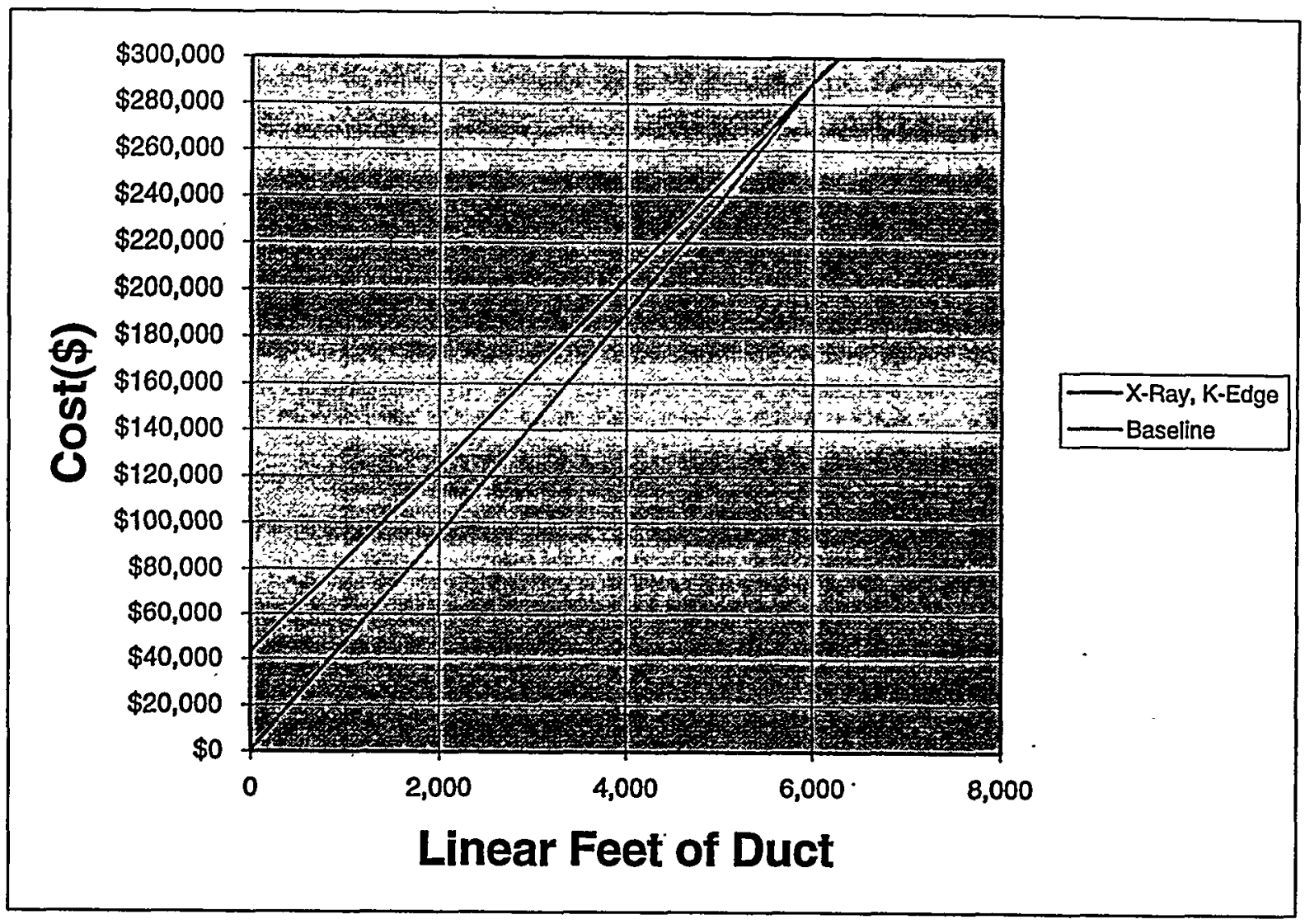

Figure 17. Break-Even Graph

Figure 18 shows the total cost of the ventilation duct assay job for three cases:

- INNOVATIVE: X-Ray, K-Edge System without the Boom (used scaffolding)

- INNOVATIVE: X-Ray, K-Edge System with Boom

- BASELINE: Nal System 
Innovative Technology -vs-Baseline-Technology

Cost Summary

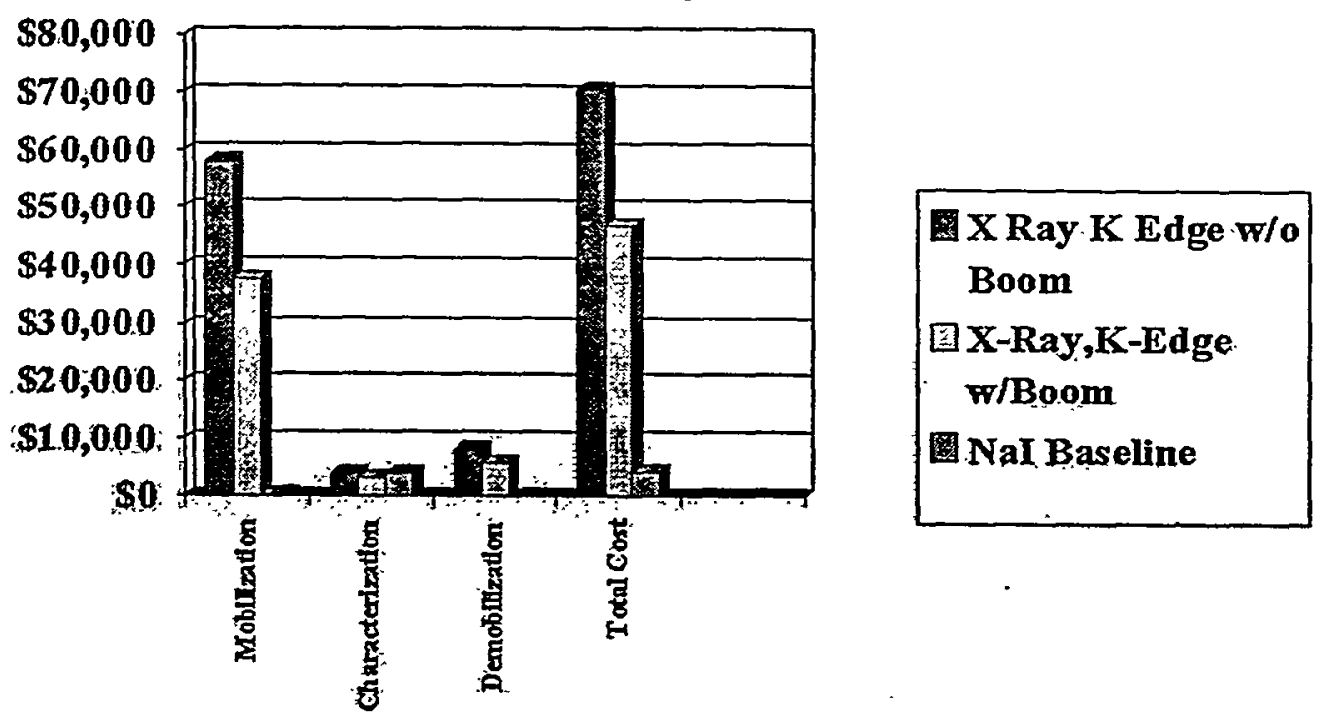

Figure 18. Cost Summary

The test engineer and vendor suggest the demonstration team could have completed the same number of measurements, assayed the same amount of ventilation ducting, in $10 \%$ less time than that documented in the Appendix B spreadsheets if moderate temperatures would have prevailed during the course of the demonstration (approximately 50 to $60^{\circ} \mathrm{F}$ ). The demonstration team experienced freezing temperatures during the technology demonstration.

The test engineer and vendor suggest the demonstration team was on a steep learning curve. Based on analysis of the daily logs, significant improvement was noticed from the first day of the demonstration to the last day. Continued deployment of the device would have created a situation where the same number of measurements, the same amount of ventilation duct, could have been assayed in $60 \%$ of the time expended for the base case.

\section{Cost Conclusions}

- The Unit Cost to perform ventilation duct assay measurements (not to include mobilization and demobilization costs) was higher for the $X$-ray, K-edge without boom case than for the $\mathrm{Nal}$ baseline case ( $\$ 48.58 / \mathrm{LF}$ vs. $\$ 47.48 / \mathrm{LF}$ ). The unit cost savings for the $\mathrm{X}$-ray, $\mathrm{K}$-edge with boom case over the $\mathrm{Nal}$ baseline technology is as follows:

\begin{tabular}{|c|c|}
\hline 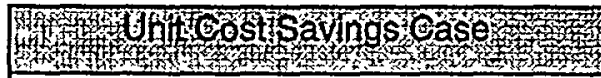 & 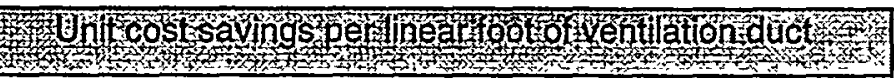 \\
\hline $\begin{array}{l}\text { X-Ray, K-Edge } \\
\text { (with adjustable boom) }\end{array}$ & $\$ 7.09 / \mathrm{LF}$ \\
\hline
\end{tabular}

- The high mobilization/demobilization cost for the X-Ray, K-Edge Heavy Metal Detection System makes "small" assay jobs cost prohibitive. Break-Even Analysis reveals a long run 
of ventilation duct (or pipe) must be assayed before X-Ray, K-Edge unit cost savings can offset the additional mobilization/demobilization costs (those X-ray, K-edge Mob/Demob costs in excess of the baseline Mob/Demob costs). The same correlation holds true on a per-shot (or assay measurement) basis.

- The X-Ray, K-Edge technology has a higher production rate than the baseline technology when the adjustable boom is used. It can assay more linear feet of ventilation duct per unit time than the Nal detection method (2.55 LF/hr vs. $2.29 \mathrm{LF} / \mathrm{hr}$ ). On a unit cost basis (not considering mobilization/demobilization costs), the X-Ray, K-Edge approach is $15 \%$ less expensive than the Nal method. Given a large enough job, the unit cost savings will overcome the fixed costs of the X-ray, K-edge mobilization and demobilization.

- Under optimum conditions (i.e., moderate temperatures and allowances made for the learning curve advantage), the ventilation duct survey could have been completed in much less time. A lower unit cost for this set of conditions and a higher unit cost savings when compared to the Nal baseline approach would have resulted in a much lower break-even point for the X-Ray, K-Edge Heavy Metal Detector.

- The mobilization/demobilization cost for the X-ray, K-edge demonstration was abnormally high. The tech demo participants felt many of the mobilization expenses were one-time expenditures associated with a first-of-a-kind field deployment. Certain expenses could be eliminated, or at a minimum reduced, if the $X$-ray, K-edge technology was deployed again. These expenses include: (1) preparation of a Worker Protection Plan (2) detailed radiation shielding calculations and (3) development of a standard operating procedure for $\mathrm{X}$-ray, K-edge use.

-

The 321-M rooftop location for the technology demonstration also added to the cost of the activity. Future ground level deployments or deployments in a room within a building could simplify the $\mathrm{X}$-ray, K-edge deployment logistics and reduce costs.

Note: This analysis simply looks at the cost implications of going with one assay technique over another: When a holdup profile of the duct contents can be easily retrieved and an increase in accuracy can be realized with the X-ray, K-edge technology, a cost-benefit analysis could show $X$-ray, $K$-edge is the best application for the problem whatever the magnitude of the job. 


\section{SECTION 6}

\section{REGULATORY AND POLICY ISSUES}

\section{Regulatory Considerations}

The operation of the X-ray K-edge Heavy Metal Detector is governed by the following federal regulations:

-10 CFR 20.1301 (a)(2)

-10 CFR 835.502 "radiation dose limits"

"entry control"

In addition, the X-ray generating device must be registered with the appropriate state or federal agency, and any restrictions of that registration must be complied with. For operation at the Savannah River Site, written approval from the WSRC Radioactive Source Control Coordinator was required.

Operation of both the X-ray K-edge detector and the baseline sodium iodide passive gamma detector required compliance with normal worker safety procedures determined by the site conditions.

Since the X-ray K-edge detector is used for nondestructive characterization of materials, there is no regulatory requirement to apply the CERCLA evaluation criteria. Some of the secondary benefits that relate to these criteria are discussed below.

\section{Safety, Risks, Benefits, and Community Reaction}

Operation of the X-ray K-edge heavy metal detector entails the risk of radiation exposure to personnel. The radiation safety issues are the same as encountered in standard X-ray radiography, and are covered above. The detector also requires use of liquid nitrogen. Standard operating procedures dictate the use of personal protective equipment (gloves and facemask) when working with liquid nitrogen.

The improved accuracy of hazardous material characterization provided by the $X$-ray K-edge detector, enables more informed decisions to be made for dismantlement operations, yielding improved worker safety and potential savings in waste disposal costs.

SRS workers, as well as the surrounding community, could benefit from a more precise and spatially-informed characterization effort by realizing wholesale savings on the cleanup costs for many SRS surplus facilities. Better characterization data would permit the decommissioning to be completed in a more cost effective manner. 


\section{SECTION 7}

\section{LESSONS LEARNED}

\section{Implementation Considerations}

\section{Equipment Logistics}

The dominant challenge of the technology demonstration was positioning a 120 pound inspection head around an object to be assayed in a reasonable amount of time. In the absence of an adjustable boom, scaffolding was erected to get the inspection head closer to the ventilation ducts (Fig. 4). To eliminate the need for scaffolding and thereby save on mobilization costs, an adjustable boom was designed and built. Although the boom was not ready in time for the X-ray, $K$-edge roof demonstration, future use on similar projects could result in significant cost savings.

\section{Power Source}

Another challenge encountered during the technology demonstration involved providing a ready source of 230 volt and 110 volt power. A portable diesel generator was used to provide the 230 volt electrical power, 110 volt electrical power was provided by a building receptacle. If the $X$-ray, K-edge technology were to be deployed at other surplus facility sites, where normal sources of power had already been de-energized, portable generator capability would be required.

\section{Radiation Protection}

Temporary shielding was used on the 321-M X-ray, K-edge technology demonstration. Based on exclusion zone radiation meter readings, the maximum radiation level, when the $X$-ray tube current setting was increased to $6 \mathrm{~mA}$, barely reached $1 \mathrm{mrem} / \mathrm{hr}{ }^{4}$ (Note: The X-ray tube current setting determines the penetrating ability of the $X$-rays.) Federal regulations limit the exclusion zone boundary value to $2 \mathrm{mrem} / \mathrm{hr}$. Without the $1 / 8$ inch steel plate shielding, the radiation level at $6 \mathrm{~mA}$ would still have been less than $2 \mathrm{mrem} / \mathrm{hr}$ : In addition, for thin-walled containers, like the 321- $M$ ventilation ducts, only 1-2 $\mathrm{mA}$ of current was needed to generate $X$-rays that could penetrate the ventilation ducts, not $6 \mathrm{~mA}$. The low radiation level readings experienced at $6 \mathrm{~mA}$, the small effect of the $1 / 8$ inch shielding, and the lower operating current during actual $X$-ray tube operations, made temporary shielding unnecessary. A more valuable lesson was to select an $X-$ ray tube with the lowest current necessary to accomplish the task.

During the demonstration, two radiation technicians took periodic surveys of the exclusion zone perimeter. The Ames operator in the hut took advantage of the shadow effect caused by the 321$M$ west wall. Nevertheless, a radiation technician sat with the K-edge operator and monitored radiation levels when the $X$-ray tube was actuated. In retrospect, the Ames operators should have been trained on the use of radiation survey instruments. Self-monitoring by the Ames operators could have avoided the cost of two rad techs for one week.

\section{Technology Limitations and Needs for Future Development}

The size and weight of the inspection head was the most limiting feature of the $X$-ray, K-edge technology. Lighter and smaller detector technologies are currently being investigated.

Recent advancements in real-time imaging have offered an alternative to the phosphor screen viewed by a CCD camera. The improved technology is an amorphous silicon X-ray imaging 
detector. This imaging unit is both smaller and lighter than the $321-\mathrm{M}$ prototype model. In addition, this imaging unit provides higher resolution and improved image contrast as well as being able to look at a larger area, i.e., up to an $12^{n} \times 16^{n}$ footprint. (The imager used on the 321$M$ project can take a snapshot of a 5 -inch square.)

The HPGe detector is the second detection device on the inspection head. A CdZnTe crystal is being laboratory tested as a replacement for the HPGe detector. The advantage to this detector is that it can be electrically cooled, making liquid nitrogen cooling unnecessary. By eliminating the nitrogen reservoir from the narrow beam detection unit, the size and weight of this detector package can be reduced.

For thin-walled containers, like the ventilation ducts assayed on the 321-M project, a lower power $X$-ray tube would have sufficed. Using a smaller $X$-ray tube could have lowered the weight on that end of the inspection head.

It was not feasible to make spectroscopic measurements at every point where the $X$-ray image indicated the presence of uranium. To obtain the total amount of uranium holdup in a region, a calibration was performed to relate the image density (in gray scale units ranging from 0 to 255) to uranium density (in $\mathrm{mg} / \mathrm{cm}^{2}$ ). Then it was possible to sum up, pixel by pixel, the total amount of uranium in a region. Each image covered a $12 \mathrm{~cm}$ by $12 \mathrm{~cm}$ region of the duct (approximately a 5 -inch square). Refinements to a recently developed computer program will make the gray scale to uranium density correlation more accurate.

Finally, the imaging unit and the HPGe detector can be laterally shifted to bring them in line with the $X$-ray tube. This operation can be done remotely from the control rack. A future design modification, will allow the entire $\mathrm{C}$-frame to be remotely moved down a short length of a ventilation duct or pipe, taking wide-angle and narrow beam shots at specified intervals. This could save a considerable amount of time between shots because far fewer exclusion zone entries and manual inspection head moves would be necessary.

\section{Technology Selection Considerations}

The X-Ray, K-Edge Heavy Metal Detection System can be used on all DOE and private sector D\&D projects where a precise, nondestructive evaluation of containerized heavy metal holdup material is required.

The X-Ray, K-Edge system is best suited for environments where container geometry and container wall thickness are not well known and/or where holdup material has an irregular distribution.

The X-Ray, K-Edge characterization technique can be used to find holdup material in process pipes and process equipment, as well as in ventilation ducts.

Due to the high mobilization/demobilization costs associated with an X-ray, K-edge deployment, small assay jobs are cost prohibitive. The $\mathrm{X}$-ray, K-edge technology is best suited to large jobs where thousands of linear feet of ventilation duct or piping must be surveyed. This technology could also be used for multiple survey jobs when the jobs are close enough and similar enough to make setups and breakdowns routine. 


\section{APPENDIX A}

\section{REFERENCES}

1. U-235 Holdup in Building 321-M Contamination Areas and Associated Exhaust Systems (U); WSRC Technical Report WSRC-TR-95-0492 (Revision 0); December 19, 1995.

2. Westinghouse Savannah River Company; "321-M Fuel Fabrication Facility Large Scale Demonstration \& Deployment Project; Technology Demonstration Test Plan for the X-Ray, KEdge Heavy Metal Detection System"; February 4, 1999.

3. R.S. Thomason; telecons with J. Lee; June, 1999.

4. SRS Long Form - Radiation Survey Logsheets; Survey Numbers: 99FDD255, 99FDD256, 99FDD267, 99FDD275, 99FDD276, 99FDD286, and 99FDD297 (for X-ray, K-edge operations from $2 / 20 / 99$ to $2 / 25 / 99$ ).

5. T. Jensen; "Standard Operating Procedures for K-Edge Heavy Metal Detector System"; February 4, 1999.

6. T. Jensen; "Standard Operating Procedures for X-Ray, K-Edge System Implementation in 321-M LSDDP at Savannah River Site"; January 28, 1999.

7. T. Jensen; "Radiation Shielding Considerations for Operation of the X-Ray, K-Edge System in the Westinghouse Savannah River Site 321-M Facility"; Ames Laboratory intemal technical report; originally issued on January 11, 1999 [revised Februáry 1, 1999].

8. D. Reilly, N. Ensslin, H. Smith, Jr., and S. Kreiner, "Passive Nondestructive Assay of Nuclear Materials", NUREG/CR-5550, US Nuclear Regulatory Commission, Washington, DC (1991).

9. H. Ottmar and H. Eberle; "The Hybrid K-Edge/K-XRF Densitometer Principles - Design Performance"; Kernforschungszentrum Karlsruhe report KFK 4590, PWA 01/91 (1991).

10. T. Jensen, T. Aljundi, and J.N. Gray; "Application of X-Ray, K-Edge Densitometry in D\&D Operations"; Proceedings of the International Conference on Decommissioning and Decontamination and on Nuclear and Hazardous Waste Management, Spectrum'98, pg. 902; The American Nuclear Society, La Grange Park, Illinois (1998).

11. R.D. McElroy, Jr.; "Radioisotope Characterization of 321-M Low Activity Waste (U); IOM NMP-NMA-930044 (Revision 0); January 19, 1994.

12. T. Jensen; telecons with J. Lee; September, 1999. 


\section{APPENDIX B}

\section{TECHNOLOGY COST COMPARISON}

\section{Introduction}

The analysis in this appendix strives to develop realistic estimates to compare costs between an innovative technology (X-Ray, K-Edge) and a baseline technology (Nal). The baseline utilizes conventional methodologies and equipment currently used for radiological surveying of contaminated duct work and piping at the Savannah River Site.

The selected activities being analyzed come from the Hazardous, Toxic, Radioactive Waste Remedial Action Work Breakdown Structure and Data Dictionary (HTRW RA WBS), USACE, 1996. The HTRW RA WBS, developed by an interagency group, was used in this analysis to provide consistency with the established national standards.

Some costs are omitted from this analysis so that it more realistically reflects a typical commercial application. The general and administrative (G\&A) markup costs for the site contractor managing the demonstration are omitted from this analysis. Overhead rates for each DOE site vary in magnitude and in the way they are applied. Decision-makers seeking site-specific costs can apply their site's G\&A rate to this analysis without having to first back out the rates used at Savannah River Site.

The following assumptions were used as the basis for the INNOVATIVE TECHNOLOGY cost analysis:

- Oversight engineering, quality assurance, and some administrative cost for the demonstration were not included.

- As applicable, equipment hourly rates for innovative pieces of equipment reflect government ownership, and are based on general guidance contained in the Office of Management and Budget's (OMB) Circular No. A-94 for Cost Effectiveness Analysis.

- Equipment unit rates are determined based on information recorded in the ACOE data collection forms.

- Standard labor rates established by the Savannah River Site for estimating D\&D work were used for those portions of work performed by local crafts.

- The analysis expresses all work on an hourly basis.

Mobilization (WBS 331.01)

Shipping Cost: Freight charge to get X-Ray, K-Edge System to SRS

Ames Labor to Ship Equipment: Ames labor required to get X-Ray, K-Edge System to SRS

Worker Protection Plan: Development of health and safety plan for the X-ray, K-edge assay operation

Radiation Shielding Calculations: Document generated to justify the recommended exclusion $z o n e$ for $X$-ray, K-edge operations. Document also specifies the special precautions required prior to conducting $X$-ray operations. 
SOP for X-Ray, K-Edge System: Development of a 321-M specific procedure for conducting Xray operations.

Permits and Reviews: Development and approval of work clearance permits, radiation work permits, work packages, an ALARA review, a temporary shielding plan, and site approvals to conduct $X$-ray operations.

SRS Physical Preparations - Manual: Labor, equipment, and materials needed to erect scaffolding, string portable lights, fabricate a portable vertical stand for the inspection head, build a plastic hut enclosure, make preps for the use of a portable generator, install shielding plates on the roof by the ventilation exhaust system, place stanchions, barriers, and signs to control access to the exclusion zone, and equip the hut for cold weather conditions.

SRS Physical Preparation - Supervisorv/Non Manual: Supervision required to control the above activities.

Equipment Setup by Ames: Unpacking and assembly of the X-ray, K-edge System.

Equipment Testing by Ames: Test-out of systems (with X-ray tube off).

Exclusion Zone Validation: Validation of recommended exclusion zone perimeter. The X-ray tube was increased in power over its anticipated operating range and radiation survey meter readings were taken to empirically validate the calculated values.

Characterization (WBS 331.17)

X-Ray, K-Edge Measurements: This activity includes calibration checks, safety interlock checks, alignment checks, acquiring images, acquiring narrow beam spectroscopic shots, vertical stand and inspection head moves, and some troubleshooting.

Download.Data - Generation of Report: Wide-angle images and narrow-beam spectroscopic traces are downloaded to a high-density disk for analysis, followed by the packaging of results and conclusions in a professional and easily understandable format.

\section{Demobilization (WBS 331.21)}

Remove Scaffolding, Shielding, and Hut - Manual: Tear down and disposition the scaffolds, temporary shielding plates, and the plastic hut.

Remove Barricades, Portable Lights, Misc. - Manual: Remove and store barricades, portable lighting, and miscellaneous support equipment used during the course of the X-ray, K-edge demonstration.

Removal Support - Supervisorv/Non Manual: Supervision required to control the above activities.

Disassemble and Package Equlpment: Breakdown of X-Ray, K-Edge System and package for shipment to Ames Lab.

Ames \& SRS Labor to Ship Equipment: Administration and coordination associated with shipping X-ray, K-edge equipment off the Savannah River Site. 
Shipping Cost: Freight charge to get X-Ray, K-Edge System to Ames Laboratory

The following assumptions were used as the basis for the BASELINE TECHNOLOGY cost analysis:

- Oversight engineering, quality assurance, and some administrative cost for the baseline technology's deployment were not included.

- As applicable, equipment hourly rates for baseline pieces of equipment reflect government . ownership, and are based on general guidance contained in the Office of Management and Budget's (OMB) Circular No. A-94 for Cost Effectiveness Analysis.

- Equipment unit rates are determined based on information recorded in the ACOE data collection forms.

- Standard labor rates established by the Savannah River Site for estimating D\&D work were used for those portions of work performed by local crafts.

- The analysis expresses all work on an hourly basis.

Mobilization (WBS 331.01)

Mobilize at site location: Stage assay equipment, grid area to be surveyed, ensure support equipment is available.

\section{Characterization (WBS 331.17)}

Calibration: Calibrate detector and multi-channel analyzer to ensure readings can be justified against an accepted standard.

Backgraund Shots: Periodic background measurements are taken that enable situationdependent corrections to be calculated and applied to the assay measurements.

Nal Readings: Actual assay measurements taken by the data acquisition team.

Final Report \& Review: Analysis of raw data and packaging of the results and conclusions in a professional and easily understandable format.

Demobilization (WBS 331.21)

Disassemble and Package Equipment: Not required for the Nal handheld detection system.

The details of the cost analysis for the innovative and baseline technologies are summarized in Tables B-1 and B-2 and B-3. 

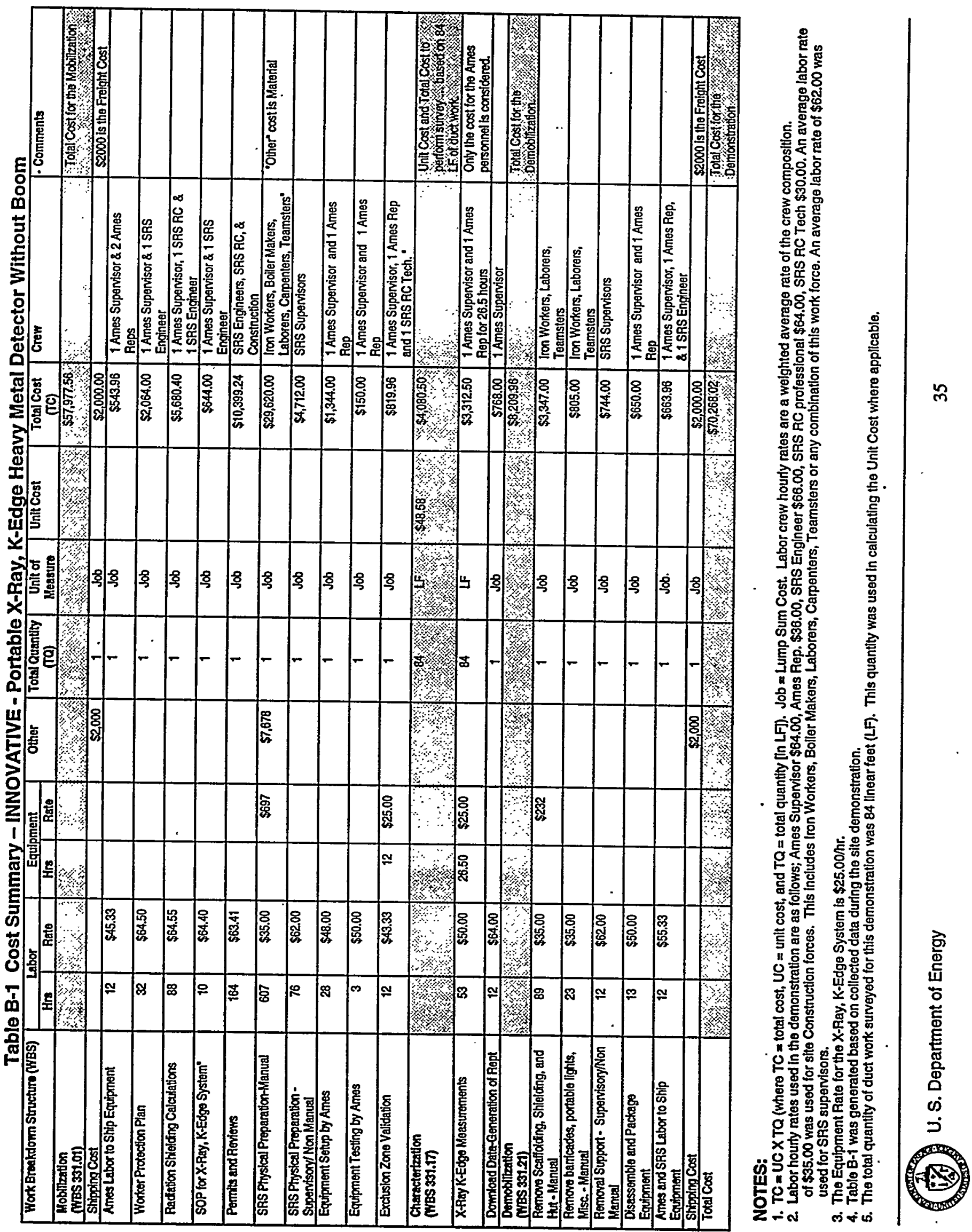


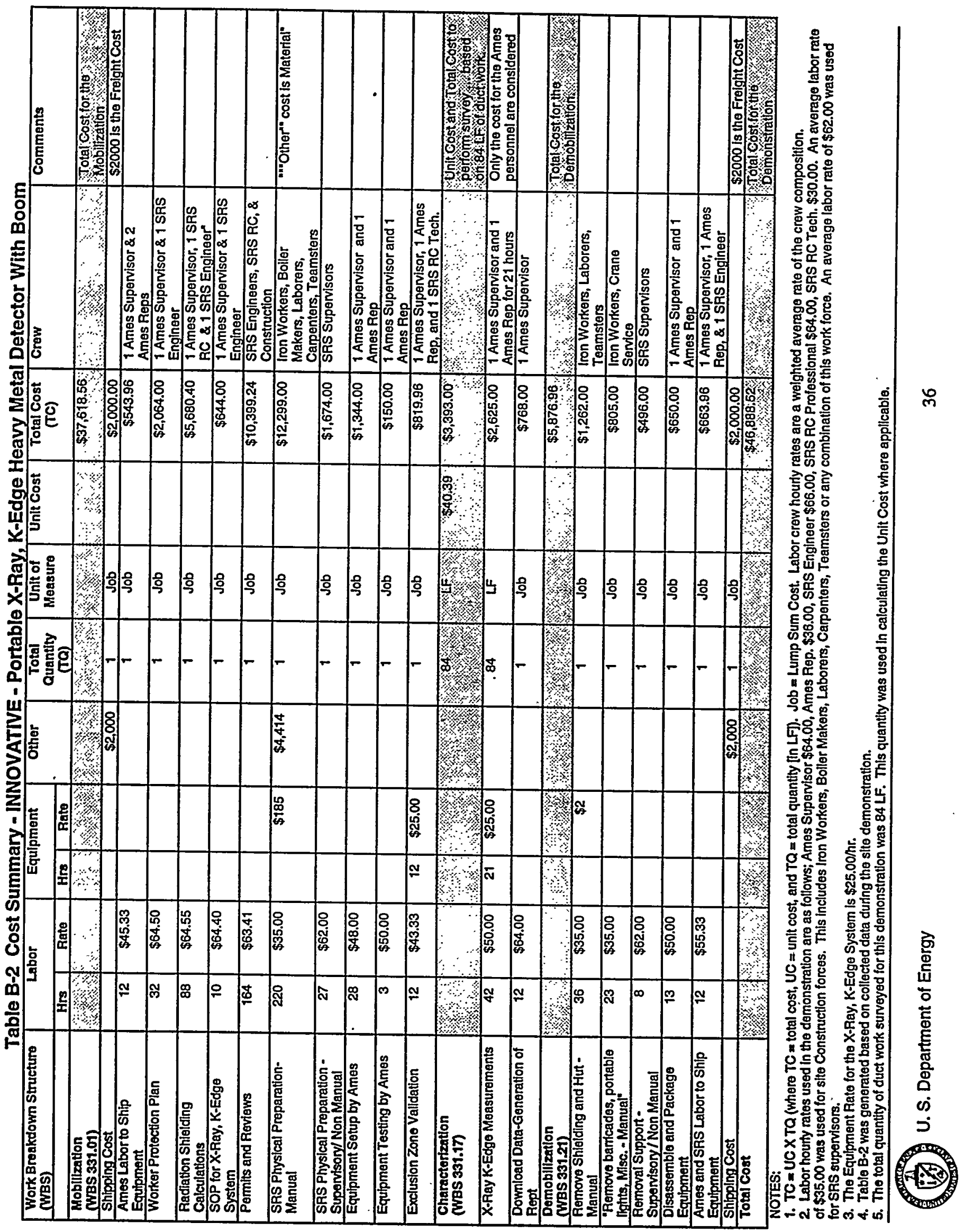



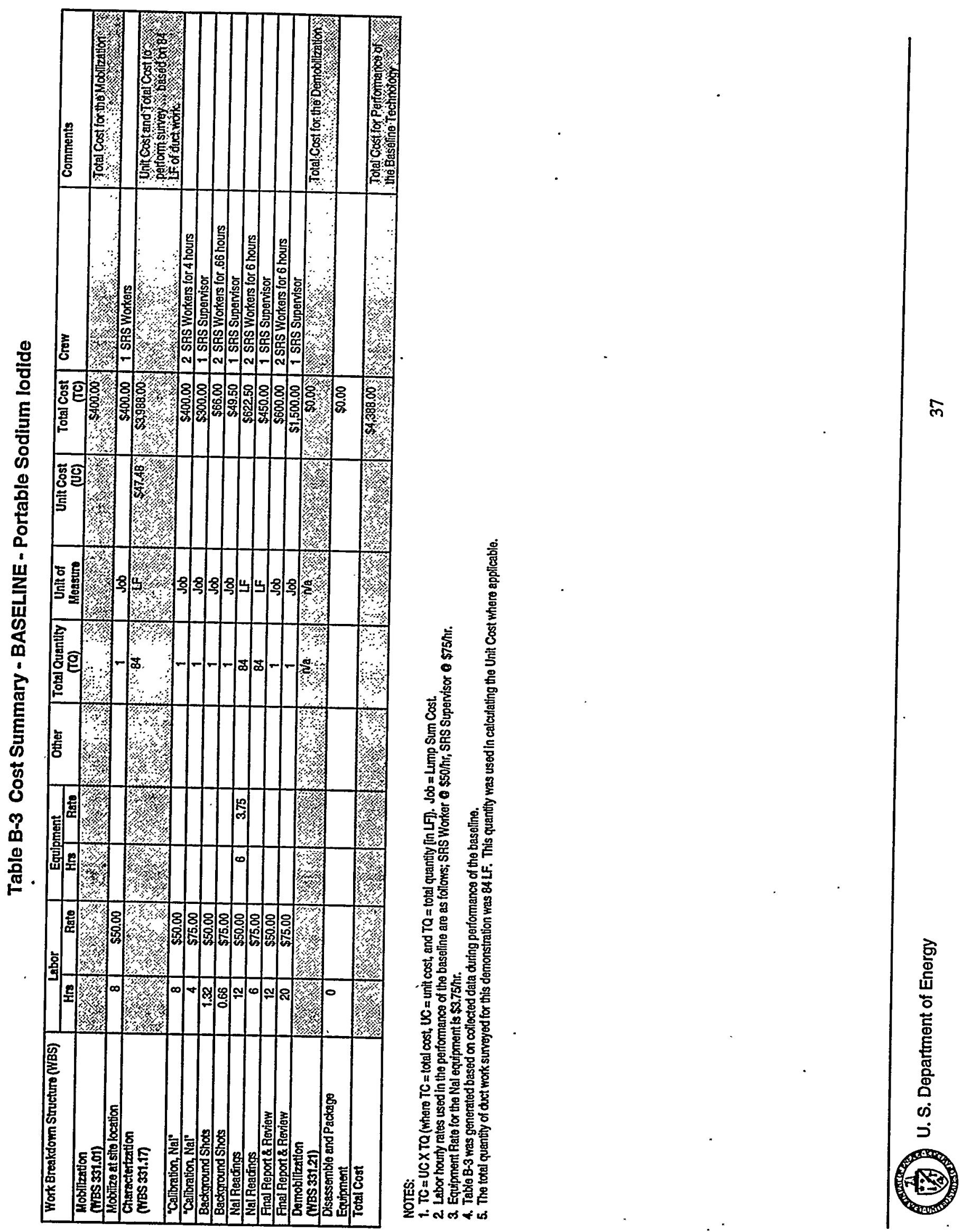